\title{
Dual Room-Temperature Fluorescent and Phosphorescent Emission in 8-Quinolinolate Osmium(II) Carbonyl Complexes: Rationalization and Generalization of Intersystem Crossing Dynamics
}

\author{
Yi-Ming Cheng, Yu-Shan Yeh, Mei-Lin Ho, and Pi-Tai Chou* \\ Department of Chemistry, National Taiwan University, Taipei 10764, Taiwan
}

Po-Shen Chen and Yun Chi*

Department of Chemistry, National Tsing Hua University, Hsinchu 30013, Taiwan

Received April 7, 2005

A new series of quinolinolate osmium carbonyl complexes were synthesized and characterized by spectroscopic methods. Single-crystal X-ray diffraction studies indicate that these complexes consist of an octahedral ligand arrangement with one chelating quinolinolate, one tfa or halide ligand, and three mutually orthogonal terminal $\mathrm{CO}$ ligands. Variation of the substituents on quinolinolate ligands imposes obvious electronic or structural effects, while changing the tfa ligand to an electron-donating iodide slightly increases the charge density on the central osmium atom. These Os(II) complexes show salient dual emissions consisting of fluorescence and phosphorescence, the spectral properties and relaxation dynamics of which have been studied comprehensively. The results, in combination with the theoretical approaches, lead us to propose that the emission mainly originates from the quinolinolate $\pi \pi^{*}$ state. Both experimental and theoretical approaches generalize various types of intersystem crossing versus those of the tris(quinolinolate) iridium $\operatorname{Ir}(\mathrm{Q})_{3}$, and their relative efficiencies were accessed on the basis of the associated frontier orbital configurations. Our results suggest that $\left\langle{ }^{1} \mathrm{~d}_{\pi} \pi^{*}\left|H_{\mathrm{so}}\right|^{3} \pi \pi^{*}\right\rangle\left(\right.$ or $\left\langle{ }^{3} \mathrm{~d}_{\pi} \pi^{*}\left|H_{\mathrm{so}}\right|^{1} \pi \pi^{*}\right\rangle$ ) in combination with a smaller $\Delta E_{S_{1}-T_{1}}$ gap (i.e., increasing the MLCT $\left(\mathrm{d}_{\pi} \pi^{*}\right)$ character) is the main driving force to induce the ultrafast $\mathrm{S}_{1} \rightarrow \mathrm{T}_{1}$ intersystem crossing in the third-row transition metal complexes, giving the strong phosphorescent emission.

\section{Introduction}

Since the first report of efficient electroluminescence from a bilayer organic light-emitting device (OLED), metal quinolinolates, such as $\mathrm{Al}(\mathrm{Q})_{3}$ with $\mathrm{Q}=8$-quinolinolate, have been the central focus for the successful development of new technologies such as the next generation of flat panel displays and other emissive systems. ${ }^{1}$ Work on derivations of Al$(\mathrm{Q})_{3}$ was also conducted in an attempt to fine-tune the emission color for OLED applications. ${ }^{2}$ Concurrently, other metal quinolinolates were synthesized and tested for applications

* To whom correspondence should be addressed. E-mail: ychi@mx.nthu.edu.tw (Y.C.); chop@nth.edu.tw (C.T.-T.).

(1) Tang, C. W.; VanSlyke, S. A. Appl. Phys. Lett. 1987, 51, 913. (b) Mitschke, U.; Bauerle, P. J. Mater. Chem. 2000, 10, 1471. (c) Kelley, T. W.; Baude, P. F.; Gerlach, C.; Ender, D. E.; Muyres, D.; Haase, M. A.; Vogel, D. E.; Theiss, S. D. Chem. Mater. 2004, 16, 4413. (d) Kulkarni, A. P.; Tonzola, C. J.; Babel, A.; Jenekhe, S. A. Chem. Mater. 2004, 16, 4556 .

4594 Inorganic Chemistry, Vol. 44, №. 13, 2005 such as the emitting materials or the electron transporting hosts in OLEDs. These materials typically contain at least one quniolinolate or substituted quinolinolate chelate that is directly coordinated to a main group element, such as a $\mathrm{Li}$, $\mathrm{Zn}, \mathrm{B}$, or Ga metal ion. ${ }^{3}$ Moreover, these complexes exhibit very high fluorescence quantum efficiency in both solid and fluid states, for which both absorption and emission bands are ascribed to the ligand-centered singlet $\pi \pi^{*}$ transitions or the intraligand charge transfer (ILCT) transitions incorporating the highest-occupied molecular orbital (HOMO), lying mainly on the phenoxide ring, and the lowest-unoccupied molecular orbital (LUMO), predominantly on the nitrogen atom. ${ }^{4}$ For the tris-substituted complexes, such as

(2) Pohl, R.; Montes, V. A.; Shinar, J.; Anzenbacher, P., Jr. J. Org. Chem 2004, 69, 1723. (b) Montes, V. A.; Li, G.; Pohl, R.; Shinar, J.; Anzenbacher, P., Jr. Adv. Mater. 2004, 16, 2001. (c) Colle, M. Gmeiner, J.; Milius, W.; Hillebrecht, H.; Brutting, W. Adv. Funct. Mater. 2003, 13, 108. Published on Web 05/25/2005 
$\operatorname{Al}(\mathrm{Q})_{3}$, subsequent $\mathrm{MO}$ calculations indicated that configuration interactions would lead to extensive mixing of all $\pi$ systems in the low-energy transitions resulting in a substantial red shift for both absorption and emission bands, relative to those of the metal complex with a single quinolinolate ligand. ${ }^{5}$

To our knowledge, surprisingly little is known about the nature of the triplet excited states of the parent 8-quniolinolate fragment (Q) because of a very inefficient $S_{1} \rightarrow T_{1}$ intersystem crossing process. ${ }^{6}$ Despite this limitation, pulse radiolysis of a benzene solution containing chelate complex $\mathrm{Al}(\mathrm{Q})_{3}$ has been shown to produce the triplet states by energy transfer from appropriate sensitizers, while the phosphorescent emission of $\mathrm{Al}(\mathrm{Q})_{3}$ was successfully recorded in an ethyl iodide matrix at $77 \mathrm{~K} .^{7}$ Obviously, in this approach, the external heavy iodine atom is the key to promoting the intersystem crossing and allowing the direct observation of an otherwise typically spin forbidden transition. Alternatively, one would expect that the related quinolinolate complexes with an internal heavy transition metal would render a more suitable model for investigating the respective triplet excited states as well as the phosphorescent emission. This delineation has led to the synthesis and characterization of a few heavy metal quinolinolate complexes of formula $\mathrm{M}(\mathrm{Q})_{n}$, with $n=2$ and $\mathrm{M}=\mathrm{Pt}$ (II) and $\mathrm{Pb}(\mathrm{II})$ or $n=3$ and $\mathrm{M}=\mathrm{Bi}$ (III) and $\operatorname{Ir}(\mathrm{III}),{ }^{8}$ together with the recently characterized highoxidation-state $\operatorname{Re}(\mathrm{VII})$ complex $\operatorname{ReO}_{3}(\mathrm{Q})^{9}$ and $\operatorname{Re}(\mathrm{I})$ carbonyl complexes of formulas $\operatorname{Re}_{2}(\mathrm{CO})_{6}(\mathrm{Q})_{2}$ and $\operatorname{Re}(\mathrm{CO})_{3^{-}}$ $(\mathrm{Q})($ solv $)$, where solv $=$ pyridine and acetonitrile. ${ }^{10} \mathrm{~A}$ particularly interesting feature is that the emission properties of these metal complexes differ greatly in their spectral patterns and relative intensities. This result implies that there are substantial variations in terms of their fundamental photophysical properties when the central metal ion and the nature of the ancillary ligands are changed.

(3) Wu, Q.; Esteghamatian, M.; Hu, N.-X.; Popovic, Z.; Enright, G.; Tao, Y.; D'Iorio, M.; Wang, S. Chem. Mater. 2000, 12, 79. (b) Schmitz, C.; Schmidt, H.-W.; Thelakkat, M. Chem. Mater. 2000, 12, 3012. (c) Leung, L. M.; Lo, W. Y.; So, S. K.; Lee, K. M.; Choi, W. K. J. Am. Chem. Soc. 2000, 122, 5640. (d) Sapochak, L. S.; Padmaperuma, A.; Washton, N.; Endrino, F.; Schmett, G. T.; Marshall, J.; Fogarty, D.; Burrows, P. E.; Forrest, S. R. J. Am. Chem. Soc. 2001, 123, 6300. (e) Sapochak, L. S.; Benincasa, F. E.; Schofield, R. S.; Baker, J. L.; Riccio, K. K. C.; Fogarty, D.; Kohlmann, H.; Ferris, K. F.; Burrows, P. E. J. Am. Chem. Soc. 2002, 124, 6119. (f) Middleton, A. J.; Marshall, W. J.; Radu, N. S. J. Am. Chem. Soc. 2003, 125, 880. (g) Qiao, J.; Wang, L. D.; Duan, L.; Li, Y.; Zhang, D. Q.; Qiu, Y. Inorg. Chem. 2004, 43, 5096. (h) Cui, Y.; Liu, Q.-D.; Bai, D.-R.; Jia, W.-L.; Tao, Y.; Wang, S. Inorg. Chem. 2005, 44, 601.

(4) Chen, C. H.; Shi, J. Coord. Chem. Rev. 1998, 171, 161. (b) Curioni, A.; Boero, M.; Andreoni, W. Chem. Phys. Lett. 1998, 294, 263. (c) Anderson, S.; Weaver, M. S.; Hudson, A. J. Synth. Met. 2000, $111-$ $112,459$.

(5) Sapochak, L. S.; Burrows, P. E.; Garbuzov, D.; Ho, D. M.; Forrest, S. R.; Thompson, M. E. J. Phys. Chem. 1996, 100, 17766. (b) Halls, M. D.; Schlegel, H. B. Chem. Mater. 2001, 13, 2632.

(6) Corsby, G. A.; Whan, R. E.; Alire, R. M. J. Chem. Phys. 1961, 34, 743. (b) Goldman, M.; Wehry, E. L. Anal. Chem. 1970, 42, 1178.

(7) Burrows, H. D.; Fernandes, M.; Seixas de Melo, J.; Monkman, A. P.; Navaratnam, S. J. Am. Chem. Soc. 2003, 125, 15310.

(8) Ballardini, R.; Indelli, M. T.; Varani, G.; Bignozzi, C. A.; Scandola, F. Inorg. Chim. Acta 1978, 31, L423. (b) Ballardini, R.; Varani, G.; Indelli, M. T.; Scandola, F. Inorg. Chem. 1986, 25, 3858. (c) Donges, D.; Nagle, J. K.; Yersin, H. Inorg. Chem. 1997, 36, 3040.

(9) Kunkely, H.; Vogler, A. Inorg. Chem. Commun. 2000, 3, 645.

(10) Kunkely, H.; Vogler, A. Inorg. Chem. Commun. 1998, 1, 398. (b) Czerwieniec, R.; Kapturkiewicz, A.; Anulewicz-Ostrowska, R.; Nowacki, J. J. Chem. Soc., Dalton Trans. 2001, 2756.
With this goal in mind, we have undertaken the determination of the structural characterization and photophysical properties of the heretofore unknown 8-quinolinolate Os(II) carbonyl complexes $\mathrm{Os}(\mathrm{CO})_{3}(\mathrm{X})(\mathrm{Q})$, where $\mathrm{X}=$ trifluoroacetate (tfa) and iodide, which were obtained in good yields using a direct solid pyrolysis method. ${ }^{11}$ To our surprise, these complexes showed rarely observed dual fluorescence and phosphorescence in solution at room temperature, which can be readily differentiated by oxygen quenching experiments. The results, in combination with relaxation dynamics and theoretical approaches, allowed us to gain detailed insights into the $\mathrm{Os}(\mathrm{CO})_{3}(\mathrm{X})(\mathrm{Q})$ properties. More importantly, generalizations for various types of intersystem crossing and hence their corresponding rates were made on an empirical basis of frontier orbital configurations. Details of the results and a discussion appear in the following sections.

\section{Experimental Section}

General Experiments. Commercially available chemical reagents were used without further purification. The reactions were monitored using Merck precoated glass TLC plates $(0.20 \mathrm{~mm}$ with fluorescent indicator $\mathrm{UV}_{254}$ ). Compounds were visualized with UV light irradiation at 254 and $365 \mathrm{~nm}$. Column chromatography was carried out using silica gel purchased from Merck (230-400 mesh). Mass spectra were obtained on a JEOL SX-102A instrument operating in an electron impact (EI) mode or a fast atom bombardment (FAB) mode. ${ }^{1} \mathrm{H}$ and ${ }^{13} \mathrm{C}$ NMR spectra were recorded on a Varian INOVA-500 instrument; chemical shifts are given with respect to the internal standard, tetramethylsilane, for ${ }^{1} \mathrm{H}$ and ${ }^{13} \mathrm{C}$ NMR data. Elemental analysis was carried out with a Heraeus CHN-O Rapid Elementary Analyzer.

Synthesis of $\mathbf{O s}(\mathbf{C O})_{3}(\mathbf{t f a})(\mathbf{Q})$. A $15 \mathrm{~mL}$ Carius tube was charged with finely pulverized $\mathrm{Os}_{2}(\mathrm{tfa})_{2}(\mathrm{CO})_{6}(100 \mathrm{mg}, 0.13 \mathrm{mmol})$ and 8-quinolinol (Q, $41 \mathrm{mg}, 0.28 \mathrm{mmol})$. The tube was degassed and sealed under a vacuum, and then it was placed into a $190{ }^{\circ} \mathrm{C}$ oven for $35 \mathrm{~min}$. After the reaction was completed, the contents were subjected to sublimation at $80^{\circ} \mathrm{C}$ and $200 \mathrm{mTorr}$ yielding $74 \mathrm{mg}$ of a yellow product, $\mathrm{Os}(\mathrm{CO})_{3}(\mathrm{tfa})(\mathrm{Q})(\mathbf{1}, 0.14 \mathrm{mmol}, 55 \%)$. Recrystallization was conducted in methanol at room temperature. It is noted that TLC should not be employed for sample purification because it would cause a marked decomposition of the sample upon contact with silica gel.

Spectral data of 1. MS (FAB, $\left.{ }^{192} \mathrm{Os}\right): \mathrm{m} / z 533\left[\mathrm{M}^{+}\right], 420\left[\mathrm{M}^{+}\right.$ $-\mathrm{CF}_{3} \mathrm{CO}_{2}$ ]. IR $\left(\mathrm{CH}_{2} \mathrm{Cl}_{2}\right): v(\mathrm{CO}) 2126(\mathrm{~s}), 2051$ (s), $2026(\mathrm{~s}) \mathrm{cm}^{-1}$. ${ }^{1} \mathrm{H}$ NMR $\left(500 \mathrm{MHz}, \mathrm{CDCl}_{3}\right): \delta 8.84\left(\mathrm{dd}, J_{\mathrm{HH}}=5.0,1.0 \mathrm{~Hz}, 1 \mathrm{H}\right)$, $8.46\left(\mathrm{dd}, J_{\mathrm{HH}}=8.3,1.3 \mathrm{~Hz}, 1 \mathrm{H}\right), 7.59\left(\mathrm{t}, J_{\mathrm{HH}}=8.0 \mathrm{~Hz}, 1 \mathrm{H}\right), 7.52$ $\left(\mathrm{dd}, J_{\mathrm{HH}}=8.5,5.0 \mathrm{~Hz}, 1 \mathrm{H}\right), 7.21\left(\mathrm{~d}, J_{\mathrm{HH}}=7.0 \mathrm{~Hz}, 1 \mathrm{H}\right), 7.17(\mathrm{~d}$, $\left.J_{\mathrm{HH}}=8.0 \mathrm{~Hz}, 1 \mathrm{H}\right) \cdot{ }^{13} \mathrm{C} \mathrm{NMR}\left(100 \mathrm{MHz}, \mathrm{CDCl}_{3}\right): \delta 176.0(\mathrm{CO})$, $169.1(\mathrm{CO}), 168.0(\mathrm{CO}), 167.0(\mathrm{C}), 162.7\left(\mathrm{q}, J_{\mathrm{CF}}=30 \mathrm{~Hz}, \mathrm{CO}\right)$, $149.8(\mathrm{CH}), 131.7(\mathrm{CH}), 130.8(\mathrm{C}), 145.0(\mathrm{CH}), 131.7(\mathrm{CH}), 130.8$ (C), $121.9(\mathrm{CH}), 117.2(\mathrm{CH}), 114.3\left(\mathrm{q}, J_{\mathrm{CF}}=230 \mathrm{~Hz}, \mathrm{CF}_{3}\right), 114.0$ (CH). ${ }^{19} \mathrm{~F}$ NMR $\left(470 \mathrm{MHz}, \mathrm{CDCl}_{3}\right): \delta-74.53$ (s, 3F). Anal. Calcd for $\mathrm{C}_{14} \mathrm{H}_{6} \mathrm{~F}_{3} \mathrm{NO}_{6} \mathrm{Os}$ : $\mathrm{C}, 31.64 ; \mathrm{H}, 1.14 ; \mathrm{N}, 2.64$. Found: $\mathrm{C}, 31.74$; $\mathrm{H}, 1.28$; $\mathrm{N}, 2.53$.

Synthesis of $\mathrm{Os}(\mathrm{CO})_{3}(\mathrm{Cl})(\mathrm{Q})$. A mixture of $\mathrm{Os}(\mathrm{CO})_{3}(\mathrm{tfa})(\mathrm{Q})$ $(100 \mathrm{mg}, 0.19 \mathrm{mmol})$ and $\mathrm{NaCl}(45 \mathrm{mg}, 0.77 \mathrm{mmol})$ in methanol $(25 \mathrm{~mL})$ was heated to reflux for $4 \mathrm{~h}$. Then, the solvent was evaporated in a vacuum, and the residue was washed with water,

(11) Gong, J.-H.; Hwang, D.-K.; Tsay, C.-W.; Chi, Y.; Peng, S.-M.; Lee, G.-H. Organometallics 1994, 13, 1720. (b) Yu, H.-L.; Chi, Y.; Liu, C.-S.; Peng, S.-M.; Lee, G.-H. Chem. Vap. Deposition 2001, 7, 245. 
Cheng et al.

filtered, and dried. The dried mass was further purified by recrystallization from $\mathrm{CH}_{2} \mathrm{Cl}_{2}$ and hexane yielding $60 \mathrm{mg}$ of yellow solid $\mathrm{Os}(\mathrm{CO})_{3}(\mathrm{Cl})(\mathrm{Q})(2,0.13 \mathrm{mmol}, 71 \%)$.

Spectral data of 2. MS (FAB, $\left.{ }^{192} \mathrm{Os}\right): \mathrm{m} / z, 533\left[\mathrm{M}^{+}\right], 420\left[\mathrm{M}^{+}\right.$ $-\mathrm{Cl}$. IR $\left(\mathrm{CH}_{2} \mathrm{Cl}_{2}\right): v(\mathrm{CO}) 2122(\mathrm{~s}), 2046(\mathrm{~s}), 2020(\mathrm{~s}) \mathrm{cm}^{-1} \cdot{ }^{1} \mathrm{H}$ $\operatorname{NMR}\left(500 \mathrm{MHz}, \mathrm{CDCl}_{3}\right): \delta 8.78\left(\mathrm{dd}, J_{\mathrm{HH}}=5.0,1.0 \mathrm{~Hz}, 1 \mathrm{H}\right)$, $8.40\left(\mathrm{dd}, J_{\mathrm{HH}}=8.3,1.3 \mathrm{~Hz}, 1 \mathrm{H}\right), 7.56\left(\mathrm{t}, J_{\mathrm{HH}}=8.0 \mathrm{~Hz}, 1 \mathrm{H}\right), 7.49$ $\left(\mathrm{dd}, J_{\mathrm{HH}}=8.3,4.8 \mathrm{~Hz}, 1 \mathrm{H}\right), 7.20\left(\mathrm{~d}, J_{\mathrm{HH}}=8.5 \mathrm{~Hz}, 1 \mathrm{H}\right), 7.13(\mathrm{~d}$, $\left.J_{\mathrm{HH}}=8.0 \mathrm{~Hz}, 1 \mathrm{H}\right) .{ }^{13} \mathrm{C} \mathrm{NMR}\left(125 \mathrm{MHz}, \mathrm{CDCl}_{3}\right): \delta 170.2(\mathrm{CO})$, 169.5 (CO), 167.1 (C), 165.5 (CO), 148.7 (CH), 142.7 (C), 140.4 $(\mathrm{CH}), 131.5(\mathrm{CH}), 131.0(\mathrm{C}), 122.1(\mathrm{CH}), 117.5(\mathrm{CH}), 113.7(\mathrm{CH})$. Anal. Calcd for $\mathrm{C}_{12} \mathrm{H}_{6} \mathrm{ClNO}_{4} \mathrm{Os}$ : C, 31.76; H, 1.33; N, 3.09 . Found: C, 31.76; H, 1.68; N, 3.23.

Synthesis of $\mathbf{O s}(\mathbf{C O})_{3}(\mathbf{I})(\mathbf{Q})$. A $15 \mathrm{~mL}$ Carius tube was charged with finely pulverized $\mathrm{Os}_{2} \mathrm{I}_{2}(\mathrm{CO})_{6}(100 \mathrm{mg}, 0.12 \mathrm{mmol})$ and 8-quinolinol (Q, $45 \mathrm{mg}, 0.27 \mathrm{mmol})$. The tube was degassed and sealed under a vacuum, and then it was placed into a $190{ }^{\circ} \mathrm{C}$ oven for $30 \mathrm{~min}$. After the reaction was completed, the contents were extracted into $\mathrm{CH}_{2} \mathrm{Cl}_{2}$, followed by sublimation at reduced pressure, yielding $75 \mathrm{mg}$ of a yellow product, $\mathrm{Os}(\mathrm{CO})_{3}(\mathrm{I})(\mathrm{Q})(\mathbf{3}, 0.14 \mathrm{mmol}$, $55 \%)$. Crystalline samples were obtained from the slow cooling of a saturated methanol solution at room temperature.

Spectral data of 3. MS (FAB, $\left.{ }^{192} \mathrm{Os}\right): \mathrm{m} / z, 547\left[\mathrm{M}^{+}\right], 420\left[\mathrm{M}^{+}\right.$ - I]. IR $\left(\mathrm{CH}_{2} \mathrm{Cl}_{2}\right): v(\mathrm{CO}) 2117$ (s), 2043 (s), 2019 (s) cm ${ }^{-1} \cdot{ }^{1} \mathrm{H}$ $\operatorname{NMR}\left(500 \mathrm{MHz}, \mathrm{CDCl}_{3}\right): \delta 8.81\left(\mathrm{~d}, J_{\mathrm{HH}}=5.0 \mathrm{~Hz}, 1 \mathrm{H}\right), 8.35(\mathrm{~d}$, $\left.J_{\mathrm{HH}}=8.5 \mathrm{~Hz}, 1 \mathrm{H}\right), 7.54\left(\mathrm{t}, J_{\mathrm{HH}}=8.0 \mathrm{~Hz}, 1 \mathrm{H}\right), 7.47\left(\mathrm{dd}, J_{\mathrm{HH}}=\right.$ $8.8,5.0 \mathrm{~Hz}, 1 \mathrm{H}), 7.15\left(\mathrm{~d}, J_{\mathrm{HH}}=8.0 \mathrm{~Hz}, 1 \mathrm{H}\right), 7.10\left(\mathrm{~d}, J_{\mathrm{HH}}=8.5\right.$ $\mathrm{Hz}, 1 \mathrm{H}) .{ }^{13} \mathrm{C} \mathrm{NMR}\left(125 \mathrm{MHz}, \mathrm{CDCl}_{3}\right): \delta 170.0(\mathrm{CO}), 169.6(\mathrm{CO})$, $167.3(\mathrm{C}), 163.3(\mathrm{CO}), 149.2(\mathrm{CH}), 143.4(\mathrm{C}), 140.2(\mathrm{CH}), 131.4$ $(\mathrm{CH}), 131.9(\mathrm{C}), 122.4(\mathrm{CH}), 117.7(\mathrm{CH}), 113.4(\mathrm{CH})$. Anal. Calcd for $\mathrm{C}_{12} \mathrm{H}_{6} \mathrm{INO}_{4} \mathrm{Os}$ : C, 26.43; $\mathrm{H}, 1.11 ; \mathrm{N}, 2.57$. Found: C, 26.75; $\mathrm{H}, 1.45 ; \mathrm{N}, 2.65$.

Synthesis of $\mathbf{O s}(\mathbf{C O})_{3}(\mathbf{t f a})(\mathbf{M Q})$. A $15 \mathrm{~mL}$ Carius tube was charged with finely pulverized $\mathrm{Os}_{2}(\mathrm{tfa})_{2}(\mathrm{CO})_{6}(100 \mathrm{mg}, 0.13 \mathrm{mmol})$ and 2-methyl-8-quinolinol (MQ, $45 \mathrm{mg}, 0.28 \mathrm{mmol}$ ). The tube was degassed and sealed under a vacuum, and then it was placed into a $190{ }^{\circ} \mathrm{C}$ oven for $45 \mathrm{~min}$. After the reaction was completed, the contents were subjected to sublimation at $110{ }^{\circ} \mathrm{C}$ and $450 \mathrm{mTorr}$, yielding $56 \mathrm{mg}$ of a yellow product, $\mathrm{Os}(\mathrm{CO})_{3}(\mathrm{tfa})(\mathrm{MQ})(\mathbf{4}, 0.10$ mmol, 40\%). Crystals suitable for X-ray diffraction studies were obtained from the slow cooling of a saturated methanol solution at room temperature.

Spectral data of 4. MS (FAB, $\left.{ }^{192} \mathrm{Os}\right): m / z, 547\left[\mathrm{M}^{+}\right], 434\left[\mathrm{M}^{+}-\right.$ $\left.\mathrm{CF}_{3} \mathrm{CO}_{2}\right]$. IR $\left(\mathrm{CH}_{2} \mathrm{Cl}_{2}\right): v(\mathrm{CO}) 2125$ (s), 2049 (s), 2025 (s) cm $\mathrm{cm}^{-1} \cdot{ }^{1} \mathrm{H}$ $\operatorname{NMR}\left(500 \mathrm{MHz}, \mathrm{CDCl}_{3}\right): \delta 8.27\left(\mathrm{~d}, J_{\mathrm{HH}}=8.5 \mathrm{~Hz}, 1 \mathrm{H}\right), 7.47(\mathrm{t}$, $\left.J_{\mathrm{HH}}=7.8 \mathrm{~Hz}, 1 \mathrm{H}\right), 7.43\left(\mathrm{~d}, J_{\mathrm{HH}}=9.0 \mathrm{~Hz}, 1 \mathrm{H}\right), 7.14\left(\mathrm{~d}, J_{\mathrm{HH}}=7.5 \mathrm{~Hz}\right.$, $1 \mathrm{H}), 7.08\left(\mathrm{~d}, J_{\mathrm{HH}}=7.5 \mathrm{~Hz}, 1 \mathrm{H}\right), 3.13(\mathrm{~s}, 3 \mathrm{H}) .{ }^{13} \mathrm{C} \mathrm{NMR}(125 \mathrm{MHz}$, $\left.\mathrm{CDCl}_{3}\right): \delta 170.4(\mathrm{CO}), 168.1(\mathrm{CO}), 168.0(\mathrm{CO}), 166.3(\mathrm{C}), 162.7$ $\left(\mathrm{q}, J_{\mathrm{CF}}=38 \mathrm{~Hz}, \mathrm{CO}\right), 159.8(\mathrm{C}), 142.5(\mathrm{C}), 141.2(\mathrm{CH}), 130.2$ $(\mathrm{CH}), 128.9(\mathrm{C}), 123.2(\mathrm{CH}), 117.2(\mathrm{CH}), 114.3\left(\mathrm{q}, J_{\mathrm{CF}}=287 \mathrm{~Hz}\right.$, $\left.\mathrm{CF}_{3}\right)$, $114.1(\mathrm{CH}), 30.4\left(\mathrm{CH}_{3}\right)$. Anal. Calcd for $\mathrm{C}_{15} \mathrm{H}_{8} \mathrm{~F}_{3} \mathrm{NO}_{6} \mathrm{Os}: \mathrm{C}$, 33.03; H, 1.48; N, 2.57. Found: C, 33.06; H, 1.66; N, 2.75.

Synthesis of $\mathrm{Os}(\mathbf{C O})_{3}(\mathbf{t f a})(\mathbf{F Q})$. A $15 \mathrm{~mL}$ Carius tube was charged with finely pulverized $\mathrm{Os}_{2}(\mathrm{tfa})_{2}(\mathrm{CO})_{6}(100 \mathrm{mg}, 0.13 \mathrm{mmol})$ and 5-fluoro-8-quinolinol (FQ, $46 \mathrm{mg}, 0.28 \mathrm{mmol}$ ). The tube was degassed and sealed under a vacuum, and then it was placed into a $190{ }^{\circ} \mathrm{C}$ oven for $20 \mathrm{~min}$. After the reaction was completed, the contents were subjected to sublimation at $110^{\circ} \mathrm{C}$ and $450 \mathrm{mTorr}$, yielding $74 \mathrm{mg}$ of a light brown product, $\mathrm{Os}(\mathrm{CO})_{3}(\mathrm{tfa})(\mathrm{FQ})(\mathbf{5}, 0.13$ $\mathrm{mmol}, 52 \%)$. Further purification was carried out by recrystallization from a methanol solution at room temperature.

Spectral data of 5. MS (FAB, $\left.{ }^{192} \mathrm{Os}\right): \mathrm{m} / z, 551\left[\mathrm{M}^{+}\right], 438\left[\mathrm{M}^{+}\right.$ $-\mathrm{CF}_{3} \mathrm{CO}_{2}$ ]. IR $\left(\mathrm{CH}_{2} \mathrm{Cl}_{2}\right): v(\mathrm{CO}) 2127$ (s), 2053 (s), 2027 (s) $\mathrm{cm}^{-1}$.
Table 1. Crystal Data and Structure Refinement Parameters for Complexes $\mathbf{4}$ and $\mathbf{5}$

\begin{tabular}{lll}
\hline & \multicolumn{1}{c}{4} & \multicolumn{1}{c}{$\mathbf{5}$} \\
\hline empirical formula & $\mathrm{C}_{15} \mathrm{H}_{8} \mathrm{~F}_{3} \mathrm{NO}_{6} \mathrm{Os}$ & $\mathrm{C}_{14} \mathrm{H}_{5} \mathrm{~F}_{4} \mathrm{NO}_{6} \mathrm{Os}$ \\
fw & 545.42 & 549.39 \\
temp & $295(2) \mathrm{K}$ & $295(2) \mathrm{K}$ \\
cryst syst & monoclinic & monoclinic \\
space group & $C 2 / c$ & $C 2 / c$ \\
$a$ & $13.5579(5) \AA$ & $19.2840(6) \AA$ \\
$b$ & $9.3166(4) \AA$ & $10.5425(3) \AA$ \\
$c$ & $25.7751(10) \AA$ & $16.8868(5) \AA$ \\
$\beta$ & $100.979(1)^{\circ}$ & $117.088(1)^{\circ}$ \\
vol, $Z$ & $3196.2(2) \AA^{3}, 8$ & $3056.5(2) \AA^{3}, 8$ \\
density (calcd) & $2.267 \mathrm{mg}^{3} \mathrm{~m}^{3}$ & $2.388 \mathrm{mg}^{3} \mathrm{~m}^{3}$ \\
abs coeff & $8.046 \mathrm{~mm}^{-1}$ & $8.424 \mathrm{~mm}^{-1}$ \\
$F(000)$ & 2048 & 2048 \\
cryst size & $0.20 \times 0.15 \times 0.10 \mathrm{~mm}^{3}$ & $0.28 \times 0.25 \times 0.23 \mathrm{~mm}^{3}$ \\
$\theta$ ranges & $2.67-27.50^{\circ}$ & $2.27-27.50^{\circ}$ \\
independent & $3679[R(\mathrm{int})=0.0406]$ & $3511[R(\mathrm{int})=0.0332]$ \\
$\quad$ reflns & & \\
data/restraints/ & $3679 / 0 / 262$ & $3511 / 0 / 236$ \\
$\quad$ parameters & & \\
GOF on $F^{2}$ & 1.039 & 1.054 \\
final $R$ indices & $R_{1}=0.0239, R_{2}=0.0507$ & $R_{1}=0.0206, R_{2}=0.0429$ \\
$\quad[I>2 \sigma(I)]$ & & \\
$R$ indices & $R_{1}=0.0295, R_{2}=0.0528$ & $R_{1}=0.0245, R_{2}=0.0441$ \\
$\quad($ all data) & & \\
largest diff & 0.596 and $-0.463 \mathrm{e} \AA^{-3}$ & 0.512 and $-0.703 \mathrm{e} \AA^{-3}$ \\
$\quad$ peak and hole & & \\
& &
\end{tabular}

Table 2. Selected Bond Lengths ( $\AA$ ) and Angles (deg) for Complex 5

\begin{tabular}{cccc}
\hline $\mathrm{Os}-\mathrm{N}(1)$ & $2.113(3)$ & $\mathrm{Os}-\mathrm{O}(4)$ & $2.053(2)$ \\
$\mathrm{Os}-\mathrm{O}(5)$ & $2.094(2)$ & $\mathrm{Os}-\mathrm{C}(1)$ & $1.924(4)$ \\
$\mathrm{Os}-\mathrm{C}(2)$ & $1.908(4)$ & $\mathrm{Os}-\mathrm{C}(3)$ & $1.891(4)$ \\
& & & \\
$\mathrm{O}(4)-\mathrm{Os}-\mathrm{N}(1)$ & $79.44(9)$ & $\mathrm{O}(4)-\mathrm{Os}-\mathrm{C}(2)$ & $174.47(12)$ \\
$\mathrm{N}(1)-\mathrm{Os}-\mathrm{C}(1)$ & $173.66(12)$ & $\mathrm{O}(5)-\mathrm{Os}-\mathrm{C}(3)$ & $174.77(12)$
\end{tabular}

${ }^{1} \mathrm{H}$ NMR $\left(500 \mathrm{MHz}, \mathrm{CDCl}_{3}\right): \delta 8.88\left(\mathrm{dd}, J_{\mathrm{HH}}=5.0,1.5 \mathrm{~Hz}, 1 \mathrm{H}\right)$, $8.67\left(\mathrm{dd}, J_{\mathrm{HH}}=8.8,1.3 \mathrm{~Hz}, 1 \mathrm{H}\right), 7.58\left(\mathrm{dd}, J_{\mathrm{HH}}=8.0,5.0 \mathrm{~Hz}\right.$, $1 \mathrm{H}), 7.34\left(\mathrm{dd}, J_{\mathrm{HF}}=9.8 \mathrm{~Hz}, J_{\mathrm{HH}}=8.8 \mathrm{~Hz}, 1 \mathrm{H}\right), 7.21\left(\mathrm{dd}, J_{\mathrm{HH}}=\right.$ $\left.8.5 \mathrm{~Hz}, J_{\mathrm{HF}}=4.0 \mathrm{~Hz}, 1 \mathrm{H}\right) .{ }^{13} \mathrm{C} \mathrm{NMR}\left(100 \mathrm{MHz}, \mathrm{CDCl}_{3}\right): \delta 169.8$ (CO), 168.7 (CO), 167.8 (CO), $163.2(\mathrm{C}), 162.7$ (q, $J_{\mathrm{CF}}=30 \mathrm{~Hz}$, CO), $150.6(\mathrm{CH}), 148.8(\mathrm{C}), 146.9(\mathrm{C}), 141.0\left(\mathrm{~d}, J_{\mathrm{CF}}=3.6 \mathrm{~Hz}\right.$, C), $135.0(\mathrm{CH}), 120.4\left(\mathrm{~d}, J_{\mathrm{CF}}=17 \mathrm{~Hz}, \mathrm{C}\right), 120.0(\mathrm{CH}), 114.9(\mathrm{~d}$, $\left.J_{\mathrm{CF}}=168 \mathrm{~Hz}, \mathrm{CH}\right), 114.7\left(\mathrm{~d}, J_{\mathrm{CF}}=62 \mathrm{~Hz}, \mathrm{CH}\right), 114.3\left(\mathrm{q}, J_{\mathrm{CF}}=\right.$ $\left.230 \mathrm{~Hz}, \mathrm{CF}_{3}\right) .{ }^{19} \mathrm{~F}$ NMR $\left(470 \mathrm{MHz}, \mathrm{CDCl}_{3}\right): \delta-74.5(\mathrm{~s}, 3 \mathrm{~F})$, $-139.3\left(\mathrm{dd}, J_{\mathrm{HF}}=8.5,4.2 \mathrm{~Hz}\right)$. Anal. Calcd for $\mathrm{C}_{14} \mathrm{H}_{5} \mathrm{~F}_{4} \mathrm{NO}_{6} \mathrm{Os}$ : C, 30.61; H, 0.92; N, 2.55. Found: C, 31.22; H, 1.15; N, 2.47.

Structural and Photophysical Measurements. Single-crystal $\mathrm{X}$-ray diffraction data were measured on a Bruker SMART Apex CCD diffractometer using $(\mathrm{Mo} K \alpha)$ radiation $(\lambda=0.71073 \AA)$. Data collection was executed using the SMART program. Cell refinement and data reduction were performed with the SAINT program. The structure was determined using the SHELXTL/PC program and refined using full-matrix least squares. All nonhydrogen atoms were refined anisotropically, whereas hydrogen atoms were placed at the calculated positions and included in the final stage of refinements with fixed positional parameters. The crystallographic refinement parameters for complexes $\mathbf{4}$ and $\mathbf{5}$ are summarized in Table 1, and selected bond distances and angles of these complexes are listed in Tables 2 and 3, respectively.

Steady-state absorption and emission spectra were recorded with a Hitachi (U-3310) spectrophotometer and an Edinburgh (FS920) fluorometer, respectively. DCM in methanol with $\Phi \sim 0.44$ served as the standard for the calculation of the emission quantum yield. Nanosecond lifetime studies were performed with an Edinburgh FL 900 photon-counting system with a hydrogen-filled or nitrogen lamp as the excitation source. The setup for the picosecond dynamical measurements consists of a femtosecond Ti-Sapphire 
Table 3. Selected Bond Lengths ( $\AA$ ) and Angles (deg) for Complex 4

$\begin{array}{lccc}\text { Os-N(1) } & 2.139(3) & \mathrm{Os}-\mathrm{O}(4) & 2.052(2) \\ \mathrm{Os}-\mathrm{O}(5) & 2.102(3) & \mathrm{Os}-\mathrm{C}(1) & 1.915(4) \\ \mathrm{Os}-\mathrm{C}(2) & 1.919(4) & \mathrm{Os}-\mathrm{C}(3) & 1.897(5) \\ & & & \\ \mathrm{O}(4)-\mathrm{Os}-\mathrm{N}(1) & 79.47(11) & \mathrm{O}(4)-\mathrm{Os}-\mathrm{C}(1) & 175.86(15) \\ \mathrm{N}(1)-\mathrm{Os}-\mathrm{C}(2) & 171.68(14) & \mathrm{O}(5)-\mathrm{Os}-\mathrm{C}(3) & 173.15(13)\end{array}$

oscillator (82 MHz, Spectra Physics). The fundamental train of pulses was pulse-selected (Neos, model N17389) to reduce its repetition rate to typically $0.8-8 \mathrm{MHz}$ and then used to produce second harmonics $(375-425 \mathrm{~nm})$ as an excitation light source. A polarizer was placed in the emission path to ensure that the polarization of the fluorescence was set at the magic angle $\left(54.7^{\circ}\right)$ with respect to that of the pump laser to eliminate the fluorescence anisotropy. An Edinburgh OB 900-L time-correlated single-photoncounting system was used as the detection system, rendering a temporal resolution of $\sim 15$ ps. Data were analyzed using the nonlinear least-squares procedure in combination with an iterative convolution method. The long-lived phosphorescence spectrum was measured in a direct laser flush experiment. Briefly, an Nd:YAG (355 nm, 8 ns, Continuum Surelite II) pumped optical parametric oscillator coupled with a second harmonic device served as a tunable excitation source. The time-resolved emission was detected by gating an intensified charge-coupled detector (ICCD, Princeton Instruments, model 576G/1) at different delay times with respect to the excitation pulse.

\section{Computational Methodology}

Time-dependent DFT calculations based on the geometry taken from X-rays of complexes $\mathbf{1 - 5}$ were carried out using a hybrid B3LYP method, ${ }^{12}$ while a double- $\zeta$ quality basis set consisting of Hay and Wadt's effective core potentials (LANL2DZ) ${ }^{13}$ was employed for iodine and osmium atoms; a $6-31 \mathrm{G}^{*}$ basis set ${ }^{14}$ was employed for the $\mathrm{H}, \mathrm{C}, \mathrm{N}, \mathrm{F}, \mathrm{Cl}$, and $\mathrm{O}$ atoms. A relativistic effective core potential (ECP) replaced the inner core electrons of Os(II), leaving the outer core $\left(5 s^{2} 5 p^{6}\right)$ electrons and the $5 d^{6}$ valence electrons. Typically, the lowest 10 triplet and singlet roots of the nonhermitian eigenvalue equations were obtained to determine the vertical excitation energies. Oscillator strengths were deduced from the dipole transition matrix elements (for singlet states only). The excited-state TDDFT calculations were carried out using Gaussian03. ${ }^{15}$

In the frontier region, neighboring orbitals are often closely spaced. In such cases, consideration of only the HOMO and LUMO may not yield a realistic description. For this reason, partial density of states (PDOS) diagrams, which incorporate a degree of overlap between the curves convoluted from neighboring energy levels, can give a more representative picture. The contribution of a group to a molecular orbital was calculated within the framework of Mulliken population analysis. The PDOS spectra were created by convoluting the molecular orbital information with Gaussian curves of unit height and fwhm of $0.5 \mathrm{eV}$. The PDOS diagrams for $\mathbf{1}$ and $\operatorname{Ir}(\mathrm{Q})_{3}$, shown in this work, are generated using the AOMix program. ${ }^{16}$

(12) Becke, A. D. Phys. Rev. A 1988, 38, 3098. (b) Lee, C.; Yang, W.; Parr, R. G. Phys. Rev. B 1988, 37, 785. (c) Miehlich, B.; Savin, A.; Stoll, H.; Preuss, H. Chem. Phys. Lett. 1989, 157, 200.

(13) Hay, P. J.; Wadt, W. R. J. Chem. Phys. 1985, 82, 270. (b) Wadt, W R.; Hay, P. J. J. Chem. Phys. 1985, 82, 284. (c) Hay, P. J.; Wadt, W. R. J. Chem. Phys. 1985, 82, 299.

(14) Hariharan, P. C.; Pople, J. A. Mol. Phys. 1974, 27, 209.

(15) Gaussian 03, revision C.02; Gaussian, Inc.: Wallingford, CT, 2004

(16) Gorelsky, S. I. AOMix, revision 6.1; http://www.sg-chem.net/. (b) Gorelsky, S. I.; Lever, A. B. P. J. Organomet. Chem. 2001, 635, 187.
Chart 1. Molecular Structures of Relevant Compounds Prepared and Discussed in This Study

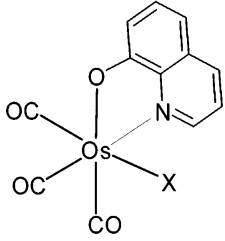

(1) $\mathrm{X}=\mathrm{CF}_{3} \mathrm{CO}_{2}$

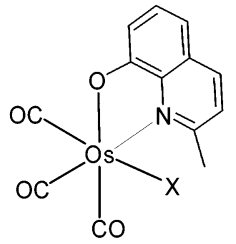

(4) $\mathrm{X}=\mathrm{CF}_{3} \mathrm{CO}_{2}$<smiles></smiles>

(5) $\mathrm{X}=\mathrm{CF}_{3} \mathrm{CO}_{2}$
(2) $\mathrm{X}=\mathrm{Cl} ;(3) \mathrm{X}=1$
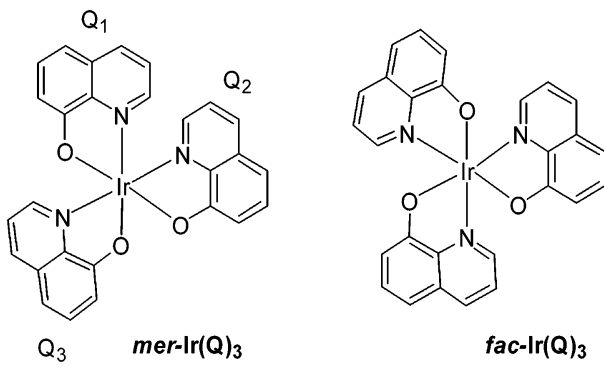

$\operatorname{Ir}(Q)_{3}$

\section{Results}

Preparation and Characterization. Three distinctive quinolinolate osmium complexes $\mathrm{Os}(\mathrm{CO})_{3}(\mathrm{tfa})(\mathrm{Q})(\mathbf{1})$, Os$(\mathrm{CO})_{3}(\mathrm{tfa})(\mathrm{MQ})(\mathbf{4})$, and $\mathrm{Os}(\mathrm{CO})_{3}(\mathrm{tfa})(\mathrm{FQ})(\mathbf{5})$ were synthesized in moderate yields from osmium carbonyl compound $\left[\mathrm{Os}(\mathrm{CO})_{3}(\mathrm{tfa})_{2}\right]_{2}$ and the quinolinol ligand using the solidstate pyrolysis technique (Chart 1). ${ }^{17}$ For each experiment, the reactants were finely pulverized and mixed thoroughly before being loaded into a Carius tube. The tube was then sealed under a vacuum and placed into a preheated oven maintained at the desired temperatures. The reactions could be visually monitored by gradual changes in color. After the reaction was completed, the tube was opened and the contents were subjected to vacuum sublimation to remove nonvolatile components, followed by recrystallization from warm methanol to yield bright yellow crystalline solids.

To further extend the synthetic scope of our approach, complex 1 was treated with $\mathrm{NaCl}$ in refluxing methanol, which led to the isolation of the respective chloridesubstituted complex $\mathrm{Os}(\mathrm{CO})_{3}(\mathrm{Cl})(\mathrm{Q})(2)$. On the other hand, the iodide-substituted analogue $\mathrm{Os}(\mathrm{CO})_{3}(\mathrm{I})(\mathrm{Q})$ (3) was prepared by heating the iodide dimer $\left[\mathrm{Os}(\mathrm{CO})_{3}(\mathrm{I})_{2}\right]_{2}{ }^{18}$ and the quinolinol ligand using the solid-state pyrolysis method mentioned above. Chart 1 depicts the molecular drawing of Os metal complexes $\mathbf{1} \mathbf{- 5}$. It should be noted that dissolution of the tfa-substituted samples $\mathbf{1}, \mathbf{4}$, and $\mathbf{5}$ into a chlorinated solvent, such as $\mathrm{CH}_{2} \mathrm{Cl}_{2}$, would produce dark brown solutions within hours. TLC analysis showed the formation of small amounts of a black intractable material that stayed at the origin of the silica gel plate, together with a fast eluting pale yellow spot from the remaining osmium complexes. Ac-

(17) Chen, Y.-L.; Sinha, C.; Chen, I.-C.; Liu, K.-L.; Chi, Y.; Yu, J.-K.; Chou, P.-T.; Lu, T.-H. Chem. Commun. 2003, 3046. (b) Gong, J.-H.; Hwang, D.-K.; Tsay, C.-W.; Chi, Y.; Peng, S.-M.; Lee, G.-H. Organometallics 1994, 13, 1720.

(18) Rosenberg, S.; Herlinger, A. W.; Mahoney, W. S.; Geoffroy, G. L. Inorg. Synth. 1989, 25, 187. 


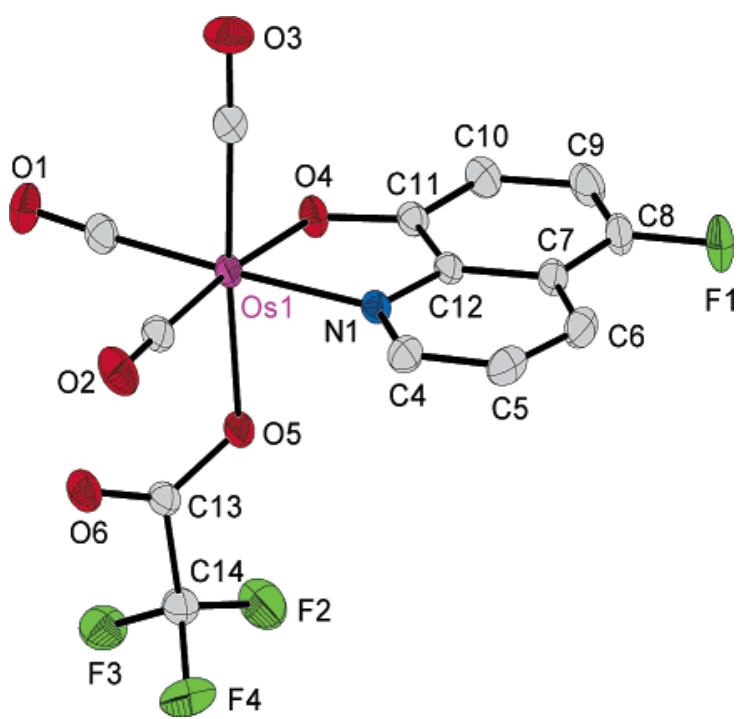

Figure 1. ORTEP diagram of complex 5 with thermal ellipsoids shown at $30 \%$ probability.

cordingly, sample purifications were best conducted in a nonchlorinated organic solvent, such as methanol or acetone, while the IR as well as NMR spectra were recorded immediately after the sample was added to the chlorinated deuterated solvents to minimize the effect of decomposition.

For the product characterization, the FAB MS analysis supported the anticipated molecular ion $\left(\mathrm{M}^{+}\right)$as well as the daughter ion products by loss of the weakly bonded anions such as the trifluoroacetate (tfa), chloride, or iodide ligands. The ${ }^{1} \mathrm{H}$ NMR spectra exhibited all of the characteristic signals derived from quinolinolate ligands, while the ${ }^{13} \mathrm{C}$ NMR analyses showed three additional signals at the downfield region $(\delta$ 170-68) from the coordinated $\mathrm{CO}$ ligands. In addition, IR analyses of all of the complexes in solution gave three intense $v(\mathrm{CO})$ stretching bands of equal intensity, implying that they could adopt the mutually orthogonal facial arrangement. It is also notable that the $v(\mathrm{CO})$ stretching frequencies of tfa-substituted complexes $\mathbf{1}, \mathbf{4}$, and $\mathbf{5}$ were essentially identical, suggesting that variations of the substituent on the quinolinolate ligands had a negligible influence on the central metal ion. In contrast, replacement of the tfa ligand of $\mathbf{1}$ with the chloride and iodide ligands, forming 2 and $\mathbf{3}$, shifted the $v(\mathrm{CO})$ stretching bands to a lower-energy side by $4-6$ and $7-9 \mathrm{~cm}^{-1}$, respectively. This systematic trend indicates a better $\pi$-donor strength for the halide ligands which then increases the electron density on the central Os(II) cation and, in turn, results in an enhanced back $\pi$ bonding to the $\mathrm{CO}$ ligands.

Unambiguous confirmation of the proposed molecular structures was provided by a single-crystal X-ray analysis of the fluorine-substituted quinolinolate complex 5. The corresponding ORTEP diagram is displayed in Figure 1, while the bond distances and angles are listed in Table 2. It is pertinent to note that the Os metal atom showed a slightly distorted octahedral ligand arrangement, encapsulated by a chelating quinolinolate ligand, together with a tfa ligand and three facial carbonyl ligands. The gross structure can be referred to that found in the closely related derivative Os-

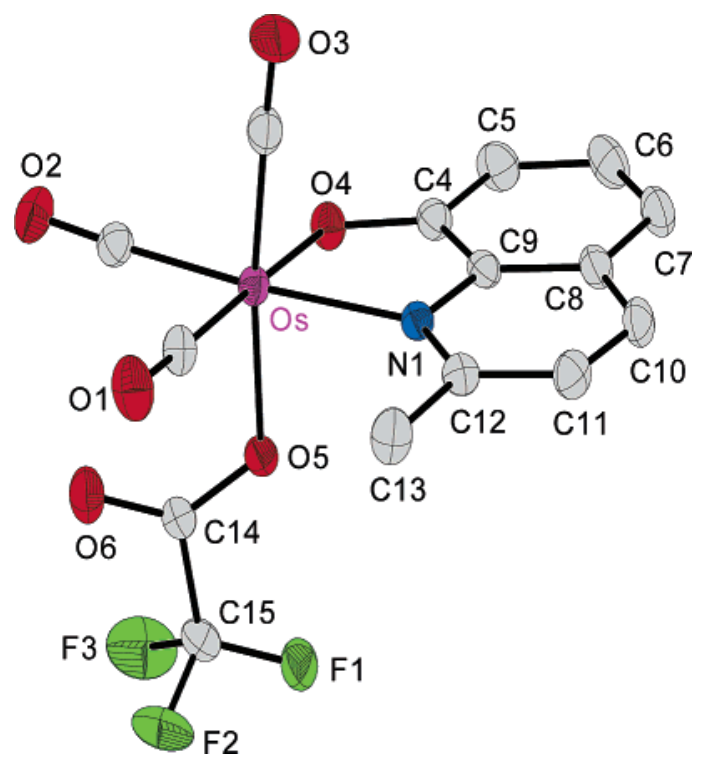

Figure 2. ORTEP diagram of complex 4 with thermal ellipsoids shown at $30 \%$ probability.

$(\mathrm{CO})_{3}(\mathrm{tfa})(\mathrm{hfac})$, where hfac $=$ hexafluoroacetylacetonate,${ }^{19}$ and homoleptic complexes, such as $\mathrm{Os}(\mathrm{CO})_{3}(\mathrm{tfa})_{2}$ and Os$(\mathrm{CO})_{3}(\mathrm{pyS})_{2}$, where pyS = pyridine-2-thionate, of which one ligand takes the chelating mode, while the second adopts the monodentate bonding mode in forming the six-coordinate geometry. ${ }^{20}$ Moreover, we also conducted the X-ray structural analysis of the 2-methyl-substituted complex, 4, to study minor variations of the ligand effect. A comparison of the ORTEP diagram (Figure 2) and the metric parameters (Tables 2 and 3) with those of $\mathbf{5}$ shows no significant deviation, except for a slight lengthening of the unique $\mathrm{Os}-\mathrm{N}$ distance from 2.113(3) $\AA$, as observed for 5, to 2.139(3) $\AA$, as observed for 4. This observation agrees with the nearly identical IR $v(\mathrm{CO})$ data from the solution state.

Photophysical Properties. The room-temperature UVvis and emission spectra of the first three complexes $\mathbf{1 , 4}$, and $\mathbf{5}$ in toluene are shown in Figure 3, while those of 1, 2, and $\mathbf{3}$ are depicted in Figure 4. The separated figures allow us to clearly visualize the spectral changes associated with the three quinolinolate ligands as well as to understand the effect of the ancillary ligands. Table 4 summarizes the peak wavelengths of the lowest-energy absorption and other important photophysical data. It is obvious that the strong absorption in the UV region $(\leq 365 \mathrm{~nm})$ with the vibronic fine structure is derived from a typical ligand-centered $\pi \pi^{*}$ transition because the corresponding transition was documented for the free quinolinol ligands. A popular assignment of metal-to-ligand charge transfer (MLCT) transition for the absorption band near 420-450 nm seems unlikely to occur on the basis of the following arguments. (i) The peak wavelength with an $\epsilon$ value of $\geq 3000 \mathrm{~cm}^{-1} \mathrm{M}^{-1}$ leads to the assignment of a generally weaker MLCT transition, which is quite inappropriate. (ii) Although the MLCT

(19) Yu, H.-L.; Chi, Y.; Liu, C.-S.; Peng, S.-M.; Lee, G.-H. Chem. Vap. Deposition 2001, 7, 245.

(20) Deeming, A. J.; Meah, M. N.; Randle, N. P.; Hardcastle, K. I. J. Chem. Soc., Dalton Trans. 1989, 2211. 


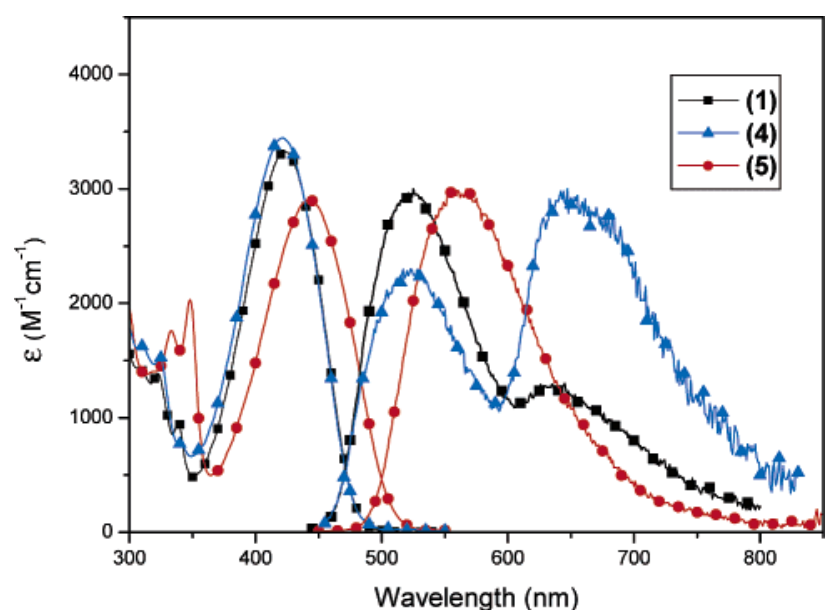

Figure 3. UV-vis absorption and normalized emission spectra of $\mathbf{1}$ (black squares), 4 (blue triangles), and $\mathbf{5}$ (red circles) in toluene at room temperature.

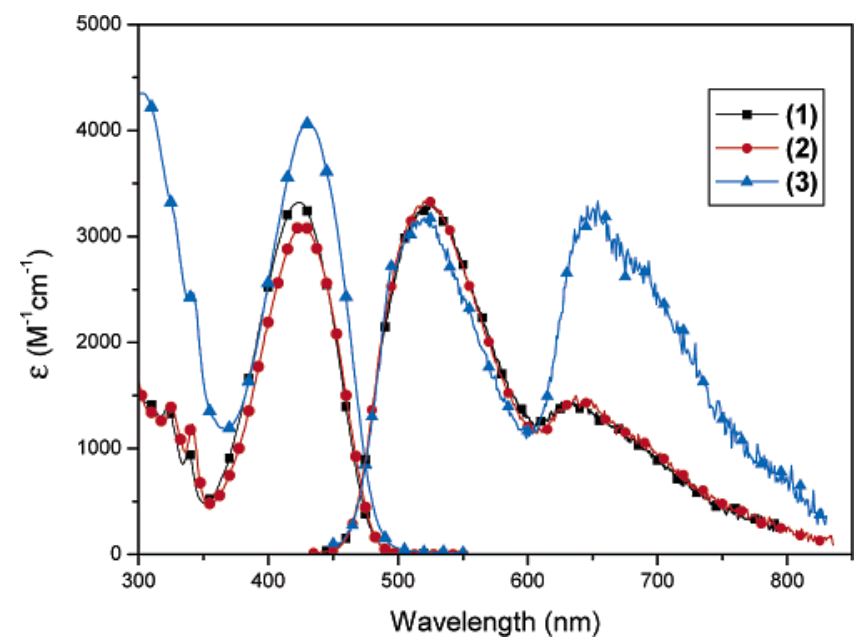

Figure 4. UV-vis absorption and normalized emission spectra of $\mathbf{1}$ (black squares), 2 (red circles), and $\mathbf{3}$ (blue triangles) in toluene at room temperature; the excitation wavelength is $500 \mathrm{~nm}$.

Table 4. Photophysical Properties of Complexes 1-5 in Degassed Toluene at Room Temperature

\begin{tabular}{cccccc}
\hline & $\begin{array}{c}\mathrm{abs}, \lambda_{\max }(\mathrm{nm}) \\
\left(\epsilon\left[\mathrm{M}^{-1} \mathrm{~cm}^{-1}\right]\right)\end{array}$ & PL, $\lambda_{\max }(\mathrm{nm})$ & $\Phi^{a}(\%)$ & fluorescence & phosphorescence ${ }^{b}$ \\
\hline $\mathbf{1}$ & $424(3300)$ & 526,635 & 1.4 & $0.55 \mathrm{~ns}$ & $33.1 \mu \mathrm{s}$ \\
$\mathbf{2}$ & $426(3100)$ & 520,635 & 1.3 & $0.50 \mathrm{~ns}$, & $35.6 \mu \mathrm{s}$ \\
$\mathbf{3}$ & $430(4100)$ & 520,650 & 2.4 & $0.15 \mathrm{~ns}$ & $3.8 \mu \mathrm{s}$ \\
$\mathbf{4}$ & $421(3400)$ & 520,650 & 0.2 & $0.21 \mathrm{~ns}$ & $21.6 \mu \mathrm{s}$ \\
$\mathbf{5}$ & $443(2900)$ & 560,689 & 1.1 & $1.10 \mathrm{~ns}$ & NA
\end{tabular}

${ }^{a}$ The solution was degassed with at least three freeze-pump-thaw cycles. The reported $\Phi$ value is the sum of fluorescence and phosphorescence. ${ }^{b}$ The phosphorescence lifetime was measured by a direct laser flash experiment.

transition might take place in the same energy region for such metal carbonyl complexes, its major involvement can be ruled out because of the occurrence of equivalent absorption in the closed shell metal complexes, such as Al$(\mathrm{Q})_{3}$, for which the MLCT transition is strictly prohibited. (iii) MLCT should reveal greater dependence on the electronic character of a central metal ion. However, this effect was not observed in the case of iodide complex $\mathbf{3}$, even though the IR $v(\mathrm{CO})$ spectrum has shown significant increases in electron density (vide supra).
Alternatively, it is more plausible to assign this band to the lowest $\pi \pi^{*}$ transition with a significant contribution from the intraligand charge transfer (ILCT) transition. This delineation shows good agreement with the $\sim 20 \mathrm{~nm}$ bathochromic shifting of the lowest-energy absorption band of complex $\mathbf{5}$, for which fluorine substitution at the 5 position is expected to markedly lower the $\pi \pi^{*}$ gap of the quinolinolate fragment because of the resonance (mesomeric) effect. Further support of these viewpoints will be elaborated in the Discussion.

Figures 3 and 4 depict the emission spectra of complexes 1-5 in degassed toluene, while the associated steady-state and dynamics data are listed in Table 4. Except for the fluorine-substituted complex, 5, the emission spectra of complexes 1-3 revealed two distinct bands, the intensity ratios for which varied according to the quinolinol ligands and the monoanionic ancillary ligands. The excitation spectra monitored at these two bands were identical, which, within experimental error, also matched the absorption spectra, indicating that the dual emission originated from the same ground-state precursor. The shorter-wavelength band, showing characteristics of short lifetime ( $\ll 2 \mathrm{~ns}$, see Table 4$)$, is a mirror image with respect to the lowest- $\pi \pi^{*} / \mathrm{ILCT}$ band and is classified as fluorescent emission, while the longwavelength band can be assigned to the respective phosphorescence on the basis of its relatively much longer lifetime $(>1 \mu \mathrm{s})$ and drastic quenching in intensity under the presence of oxygen (not shown here). In comparison, remarkably different spectral features were observed in complex $\mathbf{5}$, in which only fluorescence with a lifetime of $1.1 \mathrm{~ns}$ could be resolved. Apparently, the incorporation of a fluorine atom on the quniolinolate ligand plays a key role for the corresponding relaxation dynamics. Furthermore, Figure 4 shows the UV-vis spectra and the corresponding emission spectra of complexes 1-3, which allow us to delineate the major influences of tfa and halide ligands on the overall photophysical properties. The chloride substituent of $\mathbf{2}$ imposes only a small variation compared to that of the tfa ligand by showing very similar absorption and emission spectra. However, in the case of iodide complex $\mathbf{3}$, despite negligible changes in absorption and emission peak wavelengths, the phosphorescence was significantly increased, plausibly a result of the additional iodide heavy atom effect (vide infra). ${ }^{21}$

With regard to metal-quniolinolate complexes, dual luminescence at $77 \mathrm{~K}$ in absolute ethanol has been documented in the main group complexes, such as $\mathrm{Bi}(\mathrm{Q})_{3}$ and $\mathrm{Pb}(\mathrm{Q})_{2}{ }^{8 \mathrm{~b}}$ In contrast, because of the more efficient spinorbit interaction for the second- and third-row transition metal analogues, such as $\operatorname{Rh}(\mathrm{Q})_{3}, \operatorname{Pd}(\mathrm{Q})_{2}, \operatorname{Ir}(\mathrm{Q})_{3}, \operatorname{Pt}(\mathrm{Q})_{2}$, and $\mathrm{MeHg}$ $(\mathrm{Q}){ }^{8 \mathrm{~b}, 22}$ the fluorescent emission was completely quenched resulting in a unique strong phosphorescence. Thus, the observation of dual emission in 1-4 and even the lack of phosphorescence in $\mathbf{5}$ are of great fundamental interest. The results imply that the heavy atom effect of the central osmium atom in these complexes only transmits partially to the emitting chromophore, the net result of which is insufficient

(21) Kunkely, H.; Vogler, A. Chem. Phys. Lett. 2003, 376, 226. 
Cheng et al.

\begin{tabular}{|c|c|c|c|}
\hline entry & HOMO & LUMO \\
\hline 1 & & \\
\hline Ir(Q) & & & \\
\hline & &
\end{tabular}

Figure 5. HOMO and LUMO of complexes $\mathbf{1}, \mathbf{5}$, and $\operatorname{Ir}(\mathrm{Q})_{3}$. Note that that the lowest-lying state in both singlet and triplet manifolds is dominated by the HOMO $\rightarrow$ LUMO transition. To avoid redundancy, only complexes $\mathbf{1}$ and $\mathbf{5}$ are shown for the quinolinolate Os(II) complexes.

Table 5. Calculated Energy Levels of the $S_{1}$ and $T_{1}$ Transitions for Complexes 1-5

\begin{tabular}{|c|c|c|c|c|}
\hline & $\mathrm{nm}$ & $E(\mathrm{eV})$ & $f$ & assignments \\
\hline \multicolumn{5}{|c|}{1} \\
\hline $\mathrm{T}_{1}$ & 614.2 & 2.02 & $\sim 0$ & $\mathrm{HOMO} \rightarrow \mathrm{LUMO}$ \\
\hline $\mathrm{S}_{1}$ & 450.2 & 2.75 & 0.064 & $\mathrm{HOMO} \rightarrow$ LUMO \\
\hline \multicolumn{5}{|r|}{ (1) } \\
\hline $\mathrm{T}_{1}$ & 625.2 & 1.98 & $\sim 0$ & $\mathrm{HOMO} \rightarrow \mathrm{LUMO}$ \\
\hline $\mathrm{S}_{1}$ & 456.5 & 2.72 & 0.0542 & $\mathrm{HOMO} \rightarrow$ LUMO \\
\hline \multicolumn{5}{|c|}{3} \\
\hline $\mathrm{T}_{1}$ & 632.7 & 1.96 & $\sim 0$ & $\mathrm{HOMO} \rightarrow \mathrm{LUMO}$ \\
\hline $\mathrm{S}_{1}$ & 461.9 & 2.68 & 0.0594 & $\mathrm{HOMO} \rightarrow$ LUMO \\
\hline \multicolumn{5}{|c|}{4} \\
\hline $\mathrm{T}_{1}$ & 583.2 & 2.13 & $\sim 0$ & $\mathrm{HOMO} \rightarrow \mathrm{LUMO}$ \\
\hline $\mathrm{S}_{1}$ & 436.3 & 2.84 & 0.0525 & $\mathrm{HOMO} \rightarrow$ LUMO \\
\hline \multicolumn{5}{|c|}{5} \\
\hline $\mathrm{T}_{1}$ & 651.0 & 1.90 & $\sim 0$ & $\mathrm{HOMO} \rightarrow \mathrm{LUMO}$ \\
\hline $\mathrm{S}_{1}$ & 486.8 & 2.55 & 0.0465 & HOMO $\rightarrow$ LUMO \\
\hline
\end{tabular}

to induce an efficient intersystem crossing from the singlet to the triplet states and vice versa. Detailed mechanistic bases are elaborated in the Discussion

\section{Discussion}

Theoretical Approaches. Theoretical confirmation of the underlying basis for the photophysical properties of these osmium complexes was provided by the ab initio MO calculations. The results for complexes $\mathbf{1}-\mathbf{5}$ are shown in Figure 5 and Table 5. Figure 5 depicts the features of the highest-occupied (HOMO) and the lowest-unoccupied (LUMO) frontier orbitals mainly involved in the lower-lying transition, while the descriptions and the energy gaps of each transition are listed in Table 5. Apparently, the electron densities of the HOMO are located mainly on the phenolate fragment of the quinolinolate ligand, whereas those of the LUMO are distributed over the entire quinolinolate moiety. The results clearly indicate that the lowest-electronic transition in both $\mathrm{S}_{0} \rightarrow \mathrm{S}_{1}$ and $\mathrm{S}_{0} \rightarrow \mathrm{T}_{1}$ manifolds is dominated by $\pi \pi^{*}$ in combination with ILCT (phenolate site $(\pi) \rightarrow$ pyridine site $\left(\pi^{*}\right)$ ) character. The latter transition, in part, incorporates the transfer of electron densities from the oxygen atom of the phenolate fragment to the $\pi^{*}$ orbitals of the fused ring system. Moreover, for the HOMO of complex $\mathbf{5}$, the $\mathrm{p}_{\pi}$ orbital in the fluorine substituent conjugates with the quinolinolate $\pi$ moiety and is also involved in the lowestenergy transition. Because the fluorine atom possesses both inductive and resonant properties, the results are reminiscent of the mesomeric effect, ${ }^{23}$ in which once the substituent is located within $\pi$ conjugation, either electron-donating or electron-accepting substituents result in the decrease of electronic transition energy with a consequent bathochromic shift in the absorption and emission bands. This happens because when $\triangle \mathrm{HOMO}$ is normally larger than $\triangle \mathrm{LUMO}$, both are positive with electron-donor substituents, and when $\triangle \mathrm{HOMO}$ is smaller than $\triangle \mathrm{LUMO}$, both are negative with electron-acceptor substituents. The variations in the energy levels caused by the mesomeric effect are fully consistent with the red-shifted absorption in complex $\mathbf{5}$ compared to that in complex 1.

The lowest singlet-state transitions of 436 and $486 \mathrm{~nm}$ calculated for $\mathbf{4}$ and $\mathbf{5}$, respectively, are in good agreement with those $(\mathbf{4}, 421 \mathrm{~nm} ; \mathbf{5}, 443 \mathrm{~nm})$ obtained from the absorption spectra. Likewise, the estimated $\mathrm{S}_{0} \rightarrow \mathrm{T}_{1}$ transition of $583 \mathrm{~nm}$ for complex 4 is qualitatively consistent with observed $650 \mathrm{~nm}$ phosphorescence. The deviation of the current theoretical approach from the experimental results may be partly explained by the underestimation of the mixing of the high-density low-lying states or the less-extensive basis set used for the Os(II) atom. Moreover, a comparison of the energy gap calculated from the $\mathrm{S}_{0} \rightarrow \mathrm{T}_{1}$ transition (in the gas phase) with that obtained from phosphorescence (in solution) may not be fair because of the role of the solvent polarity effect, which normally leads to a further spectral red shift. Nevertheless, the result qualitatively predicts the tendencies of the relative energy levels of these lower-lying excited states. Despite the lack of phosphorescence, the calculation predicts the $S_{0} \rightarrow T_{1}$ transition for complex 5 to be $\sim 651 \mathrm{~nm}$. Taking into account the solvation effect, it is reasonable to predict the phosphorescence to appear at $\sim 690$ $\mathrm{nm}$. Thus, the lack of observable room-temperature phosphorescence in complex $\mathbf{5}$ may be rationalized by the relatively slow intersystem crossing in combination with the small $\mathrm{T}_{1}-\mathrm{S}_{0}$ energy gap delineated as follows.

Intersystem Crossing. As listed in Table 4, the fluorescence lifetime was measured to be $\ll 2 \mathrm{~ns}$ for complexes $\mathbf{1}-\mathbf{5}$ in toluene. In comparison, the metal-free quinolinolate anion exhibits a fluorescence decay time as long as $4.1 \mathrm{~ns}\left(k_{\mathrm{obs}}=\right.$

(22) Donges, D.; Nagle, J. K.; Yersin, H. J. Lumin. 1997, 72-74, 658. (b) Yersin, H.; Donges, D.; Nagle, J. K.; Sitters, R.; Glasbeek, M. Inorg. Chem. 2000, 39, 770. (c) Kunkely, H.; Vogler, A. J. Photochem. Photobiol. A 2001, 144, 69.

(23) Klessinger, M.; Michl, J. Excited States and Photochemistry of Organic Molecules; VCH: New York, 1995. 
$\left.2.44 \times 10^{8} \mathrm{~s}^{-1}\right)$. The observed rate of decay for complexes $\mathbf{1 - 5}$ can be expressed as

$$
k_{\mathrm{obs}}=k_{\mathrm{r}}+k_{\mathrm{nr}}+k_{\mathrm{isc}}
$$

where $k_{\text {isc }}$ is the intersystem crossing rate constant and $k_{\mathrm{r}}$ and $k_{\mathrm{nr}}$ denote the radiative and nonradiative decay rate constants, respectively, excluding the intersystem crossing. Assuming a relatively much smaller $k_{\text {isc }}$ for the quinolinolate anion, $k_{\text {isc }}$ for complexes $\mathbf{1}-\mathbf{5}$ can therefore be estimated via $k_{\text {isc }}(\mathbf{1}-\mathbf{5})=k_{\text {obs }}(\mathbf{1}-\mathbf{5})-k_{\text {obs }}$ (quinolinolate ion). As listed in Table 4, the $k_{\text {isc }}$ of $6.43 \times 10^{9} \mathrm{~s}^{-1}$ calculated for $\mathbf{3}$ is the largest among the complexes studied. Conversely, the $k_{\text {isc }}$ of $6.65 \times 10^{8} \mathrm{~s}^{-1}$ for complex 5 represents the smallest value. Moreover, for similar analogues, $\mathbf{1}$ and $\mathbf{4}$, the $k_{\text {isc }}\left(4.52 \times 10^{9}\right.$ $\left.\mathrm{s}^{-1}\right)$ in 4 is $\sim 3$-fold larger than that of $\mathbf{1}\left(1.57 \times 10^{9} \mathrm{~s}^{-1}\right)$.

To rationalize the results, one might consider the spin-forbidden nature and hence the very small $\mathrm{S}_{1} \rightarrow \mathrm{T}_{n}$ intersystem crossing (ISC) rate in the $\pi \pi^{*}$ configuration of the quinolinolate ion. Thus, perturbations, such as vibronic coupling and spin-orbit coupling, are necessary to break-down the spinforbidden nature and enhance the intersystem crossing rate. To simplify the approach, assuming that the $S_{1} \rightarrow T_{1}$ transition is the dominant ISC process, on the basis of Fermi's golden rule, the rate of intersystem crossing can be expressed as ${ }^{24}$

$$
k_{\mathrm{isc}}=\frac{2 \pi}{\hbar}\left|\left\langle\Phi_{\mathrm{T}_{1}}\left|H_{\mathrm{so}}\right| \Phi_{\mathrm{S}_{1}}\right\rangle\right|^{2}\left|\left\langle\phi_{\mathrm{v}^{\prime}} \mid \phi_{\mathrm{v}}\right\rangle\right|^{2} \rho\left(E_{\mathrm{T}_{1}}=E_{\mathrm{S}_{1}}\right)
$$

where $\Phi_{\mathrm{S}_{1}}$ and $\Phi_{\mathrm{T}_{1}}$ denote the electronic wave functions of the singlet and triplet states, respectively. The density of the final vibronic states $\left(\mathrm{T}_{1}\right)$ has the same energy as the initial states $\left(\mathrm{S}_{1}\right)$, represented by $\rho\left(E_{\mathrm{T}_{1}}=E_{\mathrm{S}_{1}}\right) . H_{\text {so }}$ is the Hamiltonian for the spin-orbit coupling, and $\phi_{\mathrm{v}}$ denotes the vibrational wave function.

For a many-electron system, ${ }^{25}$ the spin-orbit coupling Hamiltonian could be expressed as

$$
\begin{aligned}
H_{\mathrm{so}} & =\frac{1}{2 m^{2} c} \sum_{i}\left[\frac{1}{r_{i}} \frac{\partial V\left(r_{i}\right)}{\partial r_{i}}\right] \vec{L}_{i} \vec{S}_{i} \\
& =\zeta \sum_{i} \vec{L}_{i} \vec{S}_{i}
\end{aligned}
$$

where $m$ is the mass of the electron, $c$ is the velocity of light, $\vec{S}$ and $\vec{L}$ are the electron spin and orbital angular momentum operators, respectively, $r$ is the electron-nuclear distance, and $V$ is the potential. As for an oversimplified approach, if one neglects the electron shielding effect, assuming the core atom to be hydrogen-like, $H_{\text {so }}$ can be expressed as

$$
H_{\mathrm{so}}=\left(\frac{e^{2} h^{2}}{2 m^{2} c^{2} r^{3}}\right)\left[\frac{Z^{4}}{n^{3}(l+1)\left(l+\frac{1}{2}\right) l}\right]
$$

(24) Becker, R. S. Theory and Interpretation of Fluorescence and Phosphorescence; Wiley-Interscience: New York, 1969. (b) Siddique, Z. A.; Yamamoto, Y.; Ohno, T.; Nozaki, K. Inorg. Chem. 2003, 42, 6366.

(25) Fayer, M. D. Elements of Quantum Mechanics; Oxford University Press: Oxford, U.K., 2001. where $e$ and $m$ are the charge and mass of the electron, respectively, $Z$ denotes the nuclear charge of the atom, $n$ and $l$ are the principle and orbital angular momentum quantum numbers, respectively, for the electron of concern, and $r$ is the electron-nuclear distance. Apparently, in this expression of the heavy atom effect, the rate of intersystem crossing is proportional to $Z^{8}$ and inversely proportional to $r^{6}$.

For a fixed core heavy atom like Os(II) for complexes $\mathbf{1 - 5}$, the largest $k_{\text {isc }}$ value in $\mathbf{3}$ manifests the additional iodine heavy atom effect, enhancing the rate of the $S_{1} \rightarrow T_{1}$ intersystem crossing. However, replacing iodine with chlorine, forming complex $\mathbf{2}$, shows negligible enhancement in comparison to parent complex 1 (cf., $k_{\text {isc }} \approx 1.76 \times 10^{9} \mathrm{~s}^{-1}$ vs that of $1.57 \times 10^{9} \mathrm{~s}^{-1}$ in complex $\mathbf{1}$ ) because of the lighter $\mathrm{Cl}$ atom. Relative to complex $\mathbf{1}$, the addition of a 2-methyl group in 4 enhancing $k_{\text {isc }}$ by 3 -fold may tentatively be rationalized by the increase in the density of the final vibronic state $\left(\mathrm{T}_{1}\right)$, which has the same energy as the initial states $\left(S_{1}\right)$ (i.e., the increase of $\rho\left(E_{T_{1}}=E_{S_{1}}\right)$ in eq 1), although a quantitative approach is pending for resolution. For complex $\mathbf{5}$, the additional conjugation effect introduced by the fluorine atom at the 5 position of the quinolinolate chromophore, in a qualitative manner, elongates the electron-core (Os(II)) distance $r$ on average, resulting in the retardation of intersystem crossing and hence the reduction of $k_{\text {isc. }}$.

Likewise, a similar argument can be applied to the $\mathrm{T}_{1} \rightarrow$ $\mathrm{S}_{0}$ transition dipole (i.e., the radiative decay rate) which, based on an approximation of zero-order perturbation, can theoretically be expressed as

$$
\left\langle\Phi_{\mathrm{S}_{0}}|e r| \Phi_{\mathrm{T}_{1}}\right\rangle=\frac{\left\{\left\langle\Phi_{\mathrm{S}_{1}}\left|H_{\mathrm{so}_{0}}\right| \Phi_{\mathrm{T}_{1}}\right\rangle\left\langle\Phi_{\mathrm{S}_{1}}|e r| \Phi_{\mathrm{S}_{0}}\right\rangle\right\}}{E_{\mathrm{S}_{1}}-E_{\mathrm{T}_{1}}}
$$

where $E_{\mathrm{S}_{1}}$ and $E_{\mathrm{T}_{1}}$ are the energies of $\mathrm{S}_{1}$ and $\mathrm{T}_{1}$, respectively. Similar to the derivation in eq 3 , it can thus be perceived that the $\mathrm{T}_{1} \rightarrow \mathrm{S}_{0}$ transition moment, and hence the phosphorescence radiative decay $k_{\mathrm{r}}$, in addition to borrowing the intensity from the $S_{1} \rightarrow S_{0}$ transition, is also qualitatively proportional to $Z^{8} / r^{6}$. Thus, with increases in the rate of the $\mathrm{S}_{1} \rightarrow \mathrm{T}_{1}$ intersystem crossing, the $\mathrm{T}_{1} \rightarrow \mathrm{S}_{0}$ radiative decay rate increases accordingly. This viewpoint can be qualitatively supported by the increase of the intensity ratio for the phosphorescence versus the fluorescence as $k_{\text {isc }}$ increases in the same analogues, such as in $\mathbf{4}$ and $\mathbf{1}$ (or $\mathbf{2}$ and 3). As for 5, a theoretical approach predicts a $T_{1}-S_{0}$ energy gap $(\sim 651$ $\mathrm{nm}$, Table 5) much smaller than that for the rest of the complexes because of the extensive $\pi$ electron delocalization. Thus, the $\mathrm{T}_{1} \rightarrow \mathrm{S}_{0}$ decay dynamics may be dominated by the radiationless deactivation, a mechanism known as the energy gap law. ${ }^{26}$ This, in combination with the smallest $\mathrm{S}_{1}$ $\rightarrow \mathrm{T}_{1} k_{\text {isc }}$, leads to the lack of phosphorescence for $\mathbf{5}$ in the steady-state approach.

In a sharp contrast to complexes $\mathbf{1} \mathbf{- 5}$, the third-row transition metal-quinolinolate complexes, such as $\operatorname{Ir}(\mathrm{Q})_{3}$, Pt$(\mathrm{Q})_{2}$, and $\operatorname{MeHg}(\mathrm{Q})$, exhibit a unique room-temperature phosphorescence, ${ }^{8 \mathrm{~b}, 22}$ and hence an ultrafast $k_{\text {isc }}$ is expected. To gain detailed insight into the associated mechanism, we thus performed a similar theoretical approach for the me- 
Cheng et al.

Table 6. Calculated Energy Gaps of the Lowest Transition for Complexes 1-5 and $\operatorname{Ir}(\mathrm{Q})_{3}$

\begin{tabular}{lccl}
\hline complex & $\begin{array}{c}E_{\mathrm{S}-\mathrm{T}}(\mathrm{calcd}) \\
(\mathrm{kcal} / \mathrm{mol})\end{array}$ & $\begin{array}{c}E_{\mathrm{S}-\mathrm{T}}(\mathrm{exp}) \\
(\mathrm{kcal} / \mathrm{mol})\end{array}$ & \multicolumn{1}{c}{$\begin{array}{c}\text { major configurations } \\
\text { contributed to } \mathrm{S}_{1} \rightarrow \mathrm{T}_{1} \text { ISC }\end{array}$} \\
\hline $\mathbf{1}$ & 16.8 & 9.3 & ILCT $\left(\pi \pi^{*}\right)$ \\
$\mathbf{2}$ & 17.1 & 10.0 & ILCT $\left(\pi \pi^{*}\right)$ \\
$\mathbf{3}$ & 16.7 & 11.0 & ILCT $\left(\pi \pi^{*}\right)$ \\
$\mathbf{4}$ & 16.4 & 11.0 & ILCT $\left(\pi \pi^{*}\right)$ \\
$\mathbf{5}$ & 15.0 & 9.6 & ILCT $\left(\pi \pi^{*}\right)$ \\
$\operatorname{Ir}(\mathrm{Q})_{3}$ & 9.9 & N/A & MLCT $(30.8 \%) / \operatorname{LCT}\left(\pi \pi^{*}, 69.2 \%\right)$
\end{tabular}

ridional isomer of $\operatorname{Ir}(\mathrm{Q})_{3}$, and the results are shown in Figure 5 and Table 6. In this calculation, the meridional isomer was chosen to be the target molecule (Chart 1) because it represents the kinetic product of the reaction between $\mathrm{IrCl}_{3}$ and the cyclometalated ligands, ${ }^{27}$ and the respective DFT calculations on the related mer- and fac-isomers of $\operatorname{Ir}(\mathrm{ppz})_{3}$, where $\mathrm{ppz}=1$-phenylpyrazole, gave a similar picture for the HOMO and LUMO orbitals, particularly the degree of involvement of the metal d-orbital. ${ }^{27 a}$ Interestingly, instead of the dominant $\pi \pi^{*} / \mathrm{ILCT}$ transition, resolved from complexes 1-5, for $\operatorname{Ir}(\mathrm{Q})_{3}$, the lowest transition in both the singlet and triplet manifolds involves mainly mixing of MLCT and $\pi \pi^{*}$ character. The transition characters for both 1 and $\operatorname{Ir}(\mathrm{Q})_{3}$ can be clearly perceived from the PDOS spectra (see Experimental Section) shown in Figure 6, in which the electron densities contributed to each Os (or Ir) atom and quinolinolate, tfa, and CO ligand are specified. Apparently, the difference in the transition properties between $\mathbf{1 - 5}$ and $\operatorname{Ir}(\mathrm{Q})_{3}$ lies in different ligand fields, in that the electron withdrawing property of $\mathrm{CO}$, because of its provision of $\pi$ back-bond donation, further stabilizes the $\mathrm{d}_{\pi}$ orbital of the center Os(II) atom, rendering the lowest transition possessing solely a $\pi \pi^{*} / \mathrm{ILCT}$ character in $\mathbf{1 - 5}$. Conversely, as shown in Figure 5 and Table 6, for $\operatorname{Ir}(\mathrm{Q})_{3}$, both $\pi$-conjugated orbitals in quinolinolate ligand and $\mathrm{d}_{\pi}$ orbitals in the $\operatorname{Ir}(\mathrm{III})$ core participate in HOMO, whereas LUMO mainly possesses the quinolinolate $\pi^{*}$ property, giving rise to a mixing of $\pi \pi^{*} /$ MLCT character in both singlet and triplet manifolds.

On the basis of the above stance, complexes 1-5 mainly undergo ${ }^{1} \pi \pi^{*} \rightarrow{ }^{3} \pi \pi^{*}$ intersystem crossing, in which the coupling between the orbital and spin angular momentum should be small because the transition involves negligible changes of the orbital angular momentum. Thus, there is no first-order spin-orbit coupling to enhance the intersystem crossing. In contrast, as for $\operatorname{Ir}(\mathrm{Q})_{3}$, mixing of $\pi \pi^{*}$ and MLCT in the lowest singlet and triplet states leads to the $S_{1} \rightarrow T_{1}$ intersystem crossing, in part incorporating a ${ }^{1} \mathrm{~d}_{\pi} \pi^{*} \rightarrow{ }^{3} \pi \pi^{*}$ or ${ }^{1} \pi \pi^{*} \rightarrow{ }^{3} \mathrm{~d}_{\pi} \pi^{*}$ transition. Since the net effect generates the change of orbital angular momentums (i.e., $\mathrm{d}_{\pi} \rightarrow \pi$ coupled with the flip of the electron spin) the transition has

(26) Johnson, S. R.; Westmoreland, T. D.; Caspar, J. V.; Barqawi, K. R.; Meyer, T. J. Inorg. Chem. 1988, 27, 3195. (b) Caspar, J. V.; Kober, E. M.; Sullivan, B. P.; Meyer, T. J. J. Am. Chem. Soc. 1982, 104, 630. (c) Treadway, J. A.; Loeb, B.; Lopez, R.; Anderson, P. A.; Keene, F. R.; Meyer, T. J. Inorg. Chem. 1996, 35, 2242. (d) Perkins, T. A.; Pourreau, D. B.; Netzel, T. L.; Schanze, K. S. J. Phys. Chem. 1989, 93, 4511.

(27) Tamayo, A. B.; Alleyne, B. D.; Djurovich, P. I.; Lamansky, S.; Tsyba, I.; Ho, N. N.; Bau, R.; Thompson, M. E. J. Am. Chem. Soc. 2003 , 125, 7377. (b) Yang, C.-H.; Fang, K.-H.; Chen, C.-H.; Sun, I.-W. Chem. Commun. 2004, 2232.
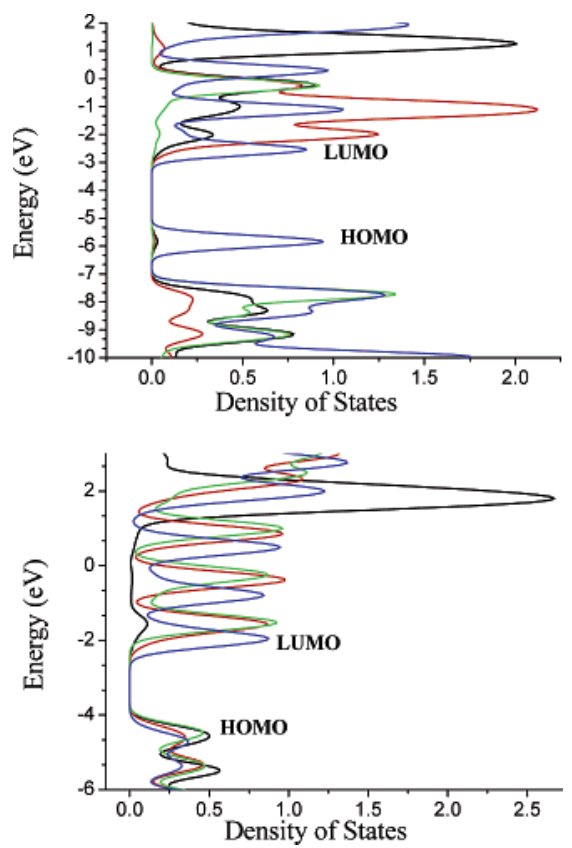

Figure 6. Partial density of state plots of $\mathbf{1}$ (upper) and $\operatorname{Ir}(\mathrm{Q})_{3}$ (lower). For 1, the contributions from the Os atom (black), quinolinolate (blue), tfa (green), and the CO ligands (red) are shown. For $\operatorname{Ir}(\mathrm{Q})_{3}$, the contributions from the Ir atom (black), Q1 (blue), Q2 (green), and Q3 (blue) are shown.

an appreciable first-order spin-orbit coupling term, resulting in a drastic enhancement of the intersystem crossing. In good agreement with this theoretical prediction, photophysical properties of the high-oxidation-state metal complex $\mathrm{ReO}_{3}$ (Q) or even the actinide metal complex Th(MQ) ${ }_{4}$ have been reported. ${ }^{9,28}$ Both showed dominant fluorescent emission, while the corresponding phosphorescence is comparably much weaker at room temperature. The lack of a strong spin-orbit interaction in these heavy metal complexes must be related to the contracted $\mathrm{d}^{0}$ electron configuration, and the interaction between the $d_{\pi}$ orbital of the central metal ion and the $\pi$ electron system of the quinolinolate ligand is thus suppressed.

Another key feature is related to the $\mathrm{S}_{1}-\mathrm{T}_{1}$ energy gap. ${ }^{29}$ The energy difference between singlet $\left(S_{1}\right)$ and triplet $\left(T_{1}\right)$ states, $\Delta E_{\mathrm{S}_{1}-\mathrm{T}_{1}}$, lies mainly in the matrix element, $J$, associated with the electron repulsion from the electron exchange, so that

$$
\Delta E_{\mathrm{S}_{1}-\mathrm{T}}=E\left(\mathrm{~S}_{1}\right)-E\left(\mathrm{~T}_{1}\right) \approx 2 J
$$

where the $J$ value is essentially equivalent to the overlap integral between the occupied electron wave functions in $\mathrm{S}_{1}$ and $\mathrm{T}_{1}$. In the case of $\mathbf{1 - 5}$ with pure $\pi \pi^{*}$ configurations in the lowest singlet and triplet states, $J$ can be expressed as

$$
J=\left\langle\pi(1) \pi^{*}(2)\left|\frac{e}{r_{12}}\right| \pi(2) \pi^{*}(1)\right\rangle
$$

where the numbers refer to the electrons occupying these orbitals and $e / r_{12}$ represents the repulsion between the

(28) Kunkely, H.; Vogler, A. Chem. Phys. Lett. 1999, 304, 187.

(29) Yersin, H.; Strasser, J. Coord. Chem. Rev. 2000, 208, 331. (b) Yersin, H.; Donges, D. Top. Curr. Chem. 2001, 214, 81. (c) Yersin, H. Top. Curr. Chem. 2004, 241, 1. 
exchanging electrons. As a simplified approach, the latter can be factored out so that $J$ is qualitatively perceived to be proportional to the overlap of the participating orbitals and can be expressed as

$$
J_{\pi, \pi^{*}} \propto\left\langle\pi(1) \pi^{*}(2) \mid \pi(2) \pi^{*}(1)\right\rangle
$$

Conversely, for the case of $\operatorname{Ir}(\mathrm{Q})_{3}$ which has mixed MLCT/ $\pi \pi^{*}$ character, the MLCT contribution to $J$ can be expressed as

$$
J_{\mathrm{d} \pi, \pi^{*}} \propto\left\langle\mathrm{d}_{\pi}(1) \pi^{*}(2) \mid \mathrm{d}_{\pi}(2) \pi^{*}(1)\right\rangle
$$

Thus, it is clear that $J_{\pi, \pi^{*}}$ is in general larger than $J_{\mathrm{d}_{\pi, \pi} \pi^{*}}$ because the integral expressed in eq 6 is greater than that in eq 7 as a result of the better orbital overlap between $\pi \pi^{*}$ than that of $\mathrm{d}_{\pi} \pi^{*}$. As a result, $\Delta E_{\mathrm{S}_{1}-\mathrm{T}_{1}}$ for $\mathbf{1}-\mathbf{5}$ is expected to be significantly larger than that of $\operatorname{Ir}(\mathrm{Q})_{3}$. This viewpoint can be further supported by the theoretical approach. As shown in Table 6, the $\Delta E_{\mathrm{S}_{1}-\mathrm{T}_{1}}$ values were calculated to be $>15 \mathrm{kcal} / \mathrm{mol}$ for $\mathbf{1} \mathbf{- 5}$. If one neglects the solvation effect, the results for 1-4 are qualitatively in agreement with the $\Delta E_{\mathrm{S}_{1}-\mathrm{T}_{1}}$ value of $>9 \mathrm{kcal} / \mathrm{mol}$ obtained from the difference in peak maxima between fluorescence and phosphorescence. Conversely, although $\Delta E_{\mathrm{S}_{1}-\mathrm{T}_{1}}$ cannot be resolved experimentally for $\operatorname{Ir}(\mathrm{Q})_{3}$, its theoretically estimated value of 9.9 $\mathrm{kcal} / \mathrm{mol}$ is smaller than that calculated for $\mathbf{1}-\mathbf{5}$ by at least $6 \mathrm{kcal} / \mathrm{mol}$.

Since the term of the density factor, $\rho\left(E_{\mathrm{T}_{1}}=E_{\mathrm{S}_{1}}\right)$, shown in eq 1 is inversely proportional to $\Delta E_{\mathrm{S}_{1}-\mathrm{T}_{1}}{ }^{2}$, the intersystem crossing of $\operatorname{Ir}(\mathrm{Q})_{3}$ is enhanced not only by the spin-orbit coupling but also by the much lower $\Delta E_{\mathrm{S}_{1}-\mathrm{T}_{1}}$ gap. Conversely, for complexes $\mathbf{1 - 5}, k_{\text {isc }}$ is expected to be much smaller, relatively, because of its much weaker spin-orbit and vibronic couplings, consistent with the experimental results. These results are also qualitatively in agreement with those reported for the $\operatorname{Ir}(\mathrm{III})$ complex, $\operatorname{Ir}(\mathrm{ppy})_{3}$, and in the related complexes $\operatorname{Ir}(\mathrm{ppy})_{2}(\mathrm{acac})$ and $\operatorname{Ir}(\mathrm{ppy})_{2}(\mathrm{bza})$, where ppy $=2$-phenylpyridine, acac $=$ acetylacetonate, and bza $=$ benzylacetonate. ${ }^{30}$ The DFT calculation showed that all of the low-lying transitions are categorized as MLCT transitions and, as expected, the metal orbitals involved in the transitions have about 50\% metal $5 \mathrm{~d}$ character, along with a significant admixture of the ligand $\pi$ character. As a result, $k_{\text {isc }}$ is expected to be ultrafast, resulting in a unity population in the $\mathrm{T}_{1}$ state.

\section{Conclusion}

In conclusion, we have synthesized a new series of quinolinolate osmium carbonyl complexes, $\mathbf{1 - 5}$. These Os complexes show salient dual emissions, consisting of fluorescence and phosphorescence, the spectral properties and relaxation dynamics of which have been studied. The results, in combination with theoretical approaches, lead us to propose that both fluorescence and phosphorescence originate mainly from the quinolinolate $\pi \pi^{*}$ state. Both the experimental and theoretical approaches generalize various types

(30) Hay, P. J. J. Phys. Chem. A 2002, 106, 1634. of intersystem crossing and hence their relative efficiencies on the basis of the mechanism incorporating spin-orbit and vibronic coupling. The $\mathrm{S}_{1}-\mathrm{T}_{1}$ intersystem crossing in complexes 1-5 with the solely ${ }^{1} \pi \pi^{*} \rightarrow{ }^{3} \pi \pi^{*}$ transition, because of its unfavorable spin-orbit and vibronic coupling and larger $\Delta E_{\mathrm{S}_{1}-\mathrm{T}_{1}}$ gap, is much slower in rate than that of $\operatorname{Ir}(\mathrm{Q})_{3}$, which involves the ${ }^{1} \mathrm{~d}_{\pi} \pi^{*} \rightarrow{ }^{3} \pi \pi^{*},{ }^{1} \pi \pi^{*} \rightarrow{ }^{3} \mathrm{~d}_{\pi} \pi^{*}$, or both types of intersystem crossing, in combination with a smaller $\Delta E_{\mathrm{S}_{1}-\mathrm{T}_{1}}$ gap (i.e., increasing the MLCT $\left(\mathrm{d}_{\pi} \pi^{*}\right)$ character). It is also believed that a similar argument holds for the case of the mixing of LMCT (ligand-to-metal charge transfer) and $\pi \pi^{*}$ characters. On the basis of this standpoint, it is reasonable to predict that third-row transition complexes possessing purely $\pi \pi^{*}$ character in both $\mathrm{S}_{1}$ and $\mathrm{T}_{1}$ may not enhance the intersystem crossing because of the lack of changes in orbital angular momentums, and hence the small spin-orbit coupling (i.e., a small $\left\langle{ }^{1} \mathrm{~d}_{\pi} \pi^{*}\left|H_{\text {so }}\right|^{3} \mathrm{~d}_{\pi} \pi^{*}\right\rangle$ term or vice versa), despite the vibronic coupling term, may be favorable because of the small $\Delta E_{\mathrm{S}_{1}-\mathrm{T}_{1}}$. It should be noted that in the aforementioned approach, we have neglected the intersystem crossing via the higher-lying triplet states (i.e., the $\mathrm{S}_{1}-\mathrm{T}_{m}(\mathrm{~m}>1)$ pathways). The breakdown of eq 1 is expected when the intersystem crossing involves $T_{n}$ states $(\mathrm{n} \geq 1)$. In this case, the spin-orbit coupling term should be replaced by $\sum_{n=1}\left\langle\Phi_{T_{n}}\left|H_{\mathrm{so}}\right| \Phi_{\mathrm{S}_{1}}\right\rangle$, and the resulting mechanism is very complicated.

Finally, in comparison to most third-row transition metal complexes utilizing the unique phosphorescence property in OLEDs,${ }^{31}$ the intrinsic dual emission in complexes such as 1- 5 renders certain perspectives in view of white light generation. As an ideal approach, if the efficiency of the $\mathrm{S}_{1}-\mathrm{T}_{1}$ intersystem crossing is $25 \%$, the intensity ratio for fluorescence versus phosphorescence should be $3: 1$, if one neglects other radiationless transition pathways (triplettriplet annihilation included) in both $S_{1}$ and $T_{1}$ states. Accordingly, after the exciton recombination, an equal intensity for fluorescence and phosphorescence should be generated statistically, achieving white light generation if both peak wavelengths are tuned optimally.

Acknowledgment. This work was funded by the National Science Council of Taiwan (Grants NSC 93-2113-M-007012 and NSC 93-2752-M-002-002-PAE).

Supporting Information Available: X-ray crystallographic data file (CIF) of complexes $\mathbf{4}$ and $\mathbf{5}$ and the complete list of authors for ref 15 . This material is available free of charge via the Internet at http://pubs.acs.org.

\section{IC0505347}

(31) Lamansky, S.; Djurovich, P.; Murphy, D.; Abdel-Razzaq, F.; Lee, H.E.; Adachi, C.; Burrows, P. E.; Forrest, S. R.; Thompson, M. E. J. Am. Chem. Soc. 2001, 123, 4304. (b) Zalis, S.; Farrell, I. R.; Vlcek, A. J. Am. Chem. Soc. 2003, 125, 4580. (c) Tamayo, A. B.; Alleyne, B. D.; Djurovich, P. I.; Lamansky, S.; Tsyba, I.; Ho, N. N.; Bau, R.; Thompson, M. E. J. Am. Chem. Soc. 2003, 125, 7377. (d) Tsuboyama, A.; Iwawaki, H.; Furugori, M.; Mukaide, T.; Kamatani, J.; Igawa, S.; Moriyama, T.; Miura, S.; Takiguchi, T.; Okada, S.; Hoshino, M.; Ueno, K. J. Am. Chem. Soc. 2003, 125, 12971. (e) Song, Y.-H.; Yeh, S.-J.; Chen, C.-T.; Chi, Y.; Liu, C.-S.; Yu, J.-K.; Hu, Y.-H.; Chou, P.-T.; Peng, S.-M.; Lee, G.-H. Adv. Funct. Mater. 2004, 14, 1221. (f) Kavitha, J.; Chang, S.-Y.; Chi, Y.; Yu, J.-K.; Hu, Y.-H.; Chou, P.-T.; Peng, S.-M.; Lee, G.-H.; Tao, Y.-T.; Chien, C.-H.; Carty, A. J. Adv. Funct. Mater. 2005, 15, 223. 